\title{
Parent-child communication on sexual and reproductive health matters: Perspectives of mothers and fathers of youth in India
}

Shireen J. Jejeebhoy

Population Council

K.G. Santhya

Population Council

Follow this and additional works at: https://knowledgecommons.popcouncil.org/departments_sbsr-pgy

Part of the Demography, Population, and Ecology Commons, Family, Life Course, and Society

Commons, Gender and Sexuality Commons, International Public Health Commons, and the Women's

Health Commons

How does access to this work benefit you? Let us know!

\section{Recommended Citation}

Jejeebhoy, Shireen J. and K.G. Santhya. 2011. "Parent-child communication on sexual and reproductive health matters: Perspectives of mothers and fathers of youth in India." New Delhi: Population Council. 


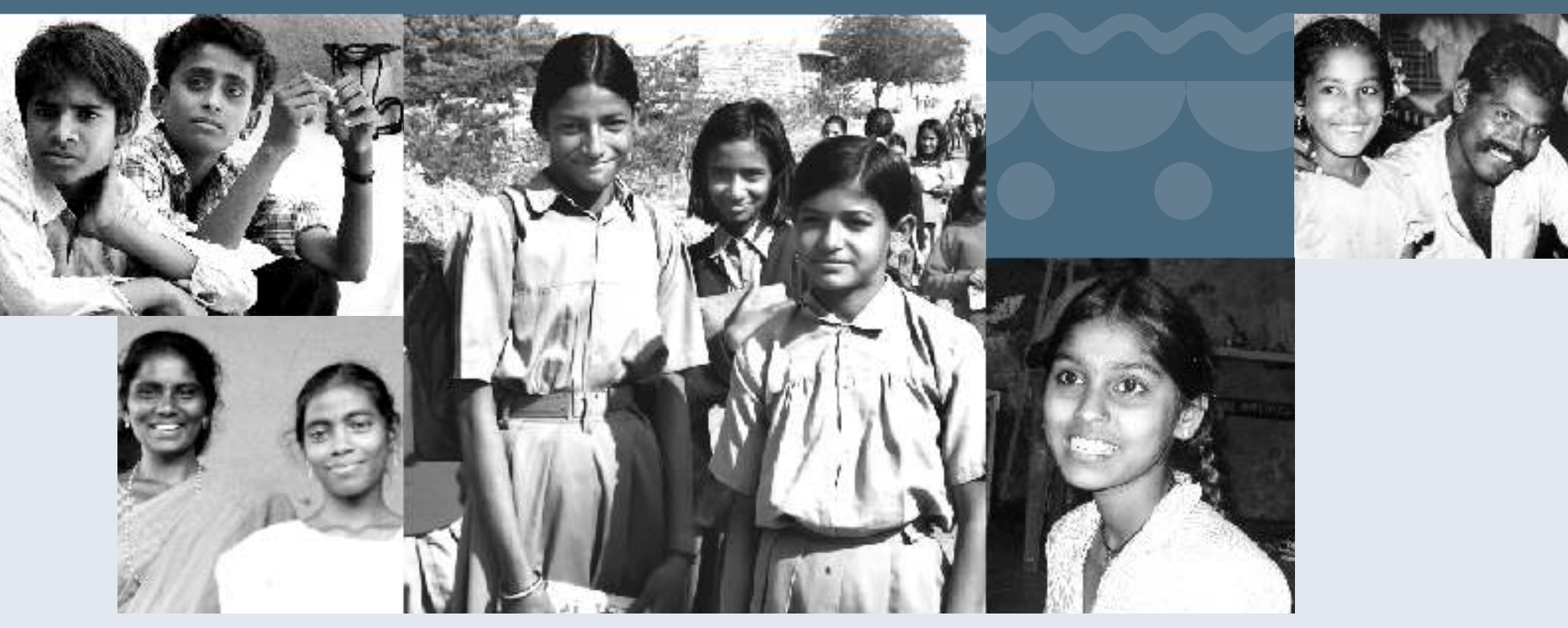

\section{Parent-child communication on sexual and reproductive health matters: Perspectives of mothers and fathers of youth in India}


This report is the result of the Youth in India: Situation and Needs study a sub-nationally representative study, undertaken for the first time in India, of key transitions experienced by young people. The study was conducted jointly by the International Institute for Population Sciences, Mumbai and the Population Council. The study covered six states of India, namely, Andhra Pradesh, Bihar, Jharkhand, Maharashtra, Rajasthan and Tamil Nadu. These six states were purposively selected to represent the different geographic and socio-cultural regions within the country, and together they represent two-fifths of the country's population. This report presents data from in-depth interviews with mothers and fathers of youth in the six states. Interviews covered a wide range of themes, including parental perspectives on their children's life, aspirations for their future and extent of communication with their children with special emphasis on communication about matters relating to the physical changes associated with puberty, sex, pregnancy and sexually transmitted infections/HIV.

For additional copies of this report, please contact:

Population Council

Zone 5-A, Ground Floor

India Habitat Centre

Lodi Road

New Delhi -110003

Phone: 011-2464 2901/02

Email: info-india@popcouncil.org

Web site: http://www.popcouncil.org/asia/india/html

The Population Council is an international, non-profit, non-governmental organisation that seeks to improve the well-being and reproductive health of current and future generations around the world and to help achieve a humane, equitable and sustainable balance between people and resources. The Council conducts biomedical, social science and public health research, and helps build research capacities in developing countries.

\section{Copyright (C) 2011 Population Council}

Suggested citation: Jejeebhoy, S. J. and K. G. Santhya. 2011. "Parent-child communication on sexual and reproductive health matters: Perspectives of mothers and fathers of youth in India." New Delhi: Population Council. 


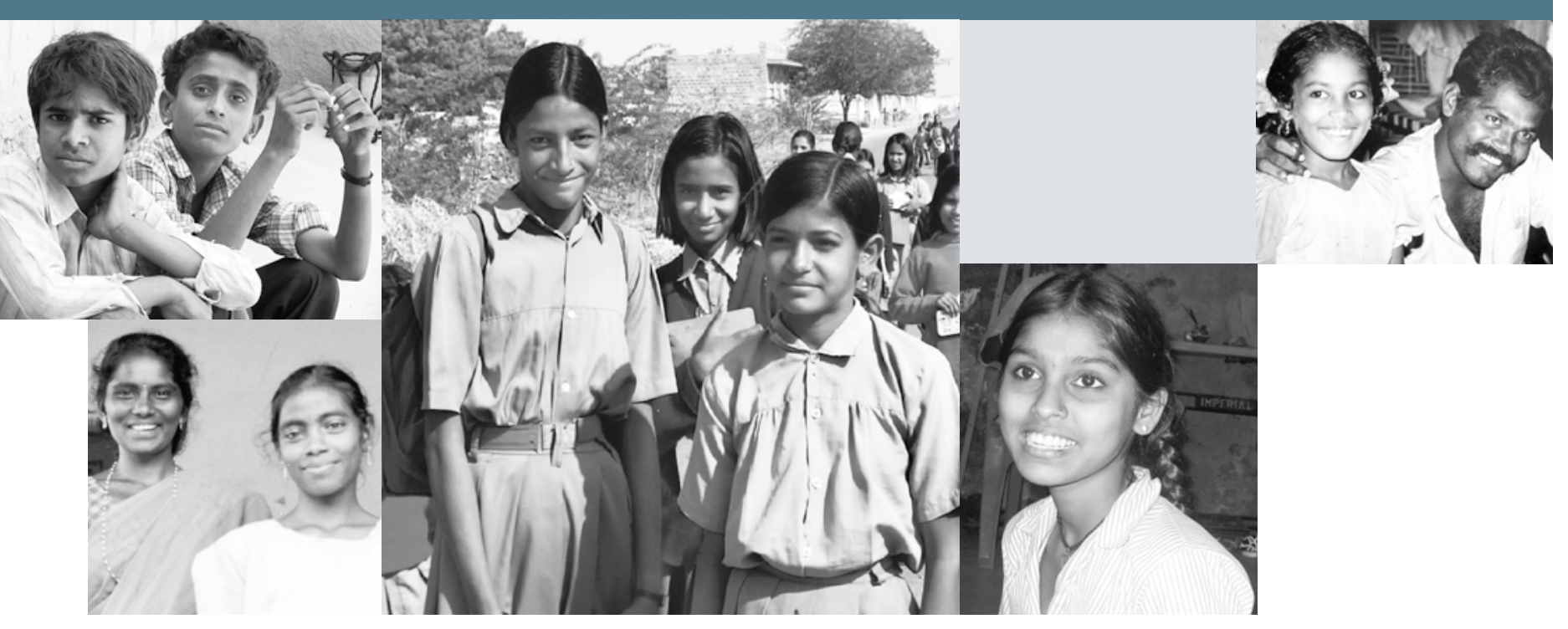

\section{Parent-child communication on sexual and reproductive health matters: Perspectives of mothers and fathers of youth in India}

Shireen J. Jejeebhoy

K.G. Santhya

Population Council 



\section{Contents}

Study setting

Methodology

Data

Analysis

Characteristics of respondents $\quad 5$

Limitations

Structure of the report

Chapter 2: Parent-child communication on non-sensitive matters

Parent-child communication in Bihar, Jharkhand and Rajasthan: Authoritarian $\quad 7$

Parent-child communication in Andhra Pradesh, Maharashtra and Tamil Nadu: Less authoritarian 12

Summary

Chapter 3: Communication about sexual and reproductive health matters

Parent perspectives on communication about the physical changes associated with puberty

Communication about matters relating to sex, pregnancy and/or sexually transmitted infections/HIV 22

Summary

Chapter 4: Obstacles to communication about sexual and reproductive health matters

Cultural norms and unacceptability of discussion on sexual and reproductive health matters

Discomfort in discussing sexual and reproductive health matters: Lack of awareness and embarrassment 31

Children come to know about sexual and reproductive health matters on their own 34

Fears that children will go astray if given information about sexual and reproductive health matters 37

Summary

Chapter 5: Perspectives of parents who favour the provision of information on sexual and reproductive health matters to their children 
Recommendations for programmes

Inform parents about sexual and reproductive health matters

Break down parents' misconceptions about communicating with children on sensitive matters

Ensure that communication about menstruation is timely and comprehensive

Address discomfort and embarrassment experienced by both parents and children

Enable parents and young people to question prevailing norms

Make efforts towards more gender egalitarian and open communication

Promote sexuality education in the school setting and dispel parental fears about its provision

\section{List of tables}

Table 1.1 Number of in-depth interviews conducted with parents, by state 4

Table 1.2 Socio-demographic characteristics of study participants 6

Table $2.1 \quad$ The nature of parent-child communication: Parental perspectives on communication about general matters

Table 3.1 Extent of communication between parents and daughters about the physical changes associated with puberty

Table 3.2 Extent of communication between parents and sons about the physical changes associated with puberty

Table 3.3 Extent of communication between parents and daughters/sons about sexual and reproductive health matters

Table 4.1 Reasons for absence of discussion between parents and sons/daughters on sexual and reproductive health matters

Table 5.1 Parent preferences about whether youth should be informed about sexual and reproductive health matters 


\section{Acknowledgements}

The Youth in India: Situation and Needs study is a sub-nationally representative study, undertaken for the first time in India, of key transitions experienced by young people. The study was conducted jointly by the International Institute for Population Sciences, Mumbai, and the Population Council. The study covered six states of India, namely, Andhra Pradesh, Bihar, Jharkhand, Maharashtra, Rajasthan and Tamil Nadu. These six states were purposively selected to represent the different geographic and socio-cultural regions within the country, and together they represent two-fifths of the country's population. This report presents data from in-depth interviews with mothers and fathers of youth in the six states. Interviews covered a wide range of themes, parental perspectives on their children's life, aspirations for their future and extent of communication with their children with special emphasis on communication about matters relating to the physical changes associated with puberty, sex, pregnancy and sexually transmitted infections/HIV.

We would like to express our gratitude to our colleagues in the International Institute for Population Sciences, Mumbai, especially, Drs Faujdar Ram, Usha Ram and Sanjay Mohanty, who played a major role in ensuring the smooth completion of this phase of research, and for their inputs in and suggestions for the analysis.

The study received generous financial support from the John D. and Catherine T. MacArthur Foundation and the David and Lucile Packard Foundation; we are grateful for the financial support as well as the thoughtful comments and suggestions provided by Lester Coutinho of the Packard Foundation and Poonam Muttreja and Dipa Nag Chowdhury of the MacArthur Foundation over the course of the project.

Additional support was received from the Ford Foundation to analyse data on parent-child interaction and parental perspectives on young people's transition to adulthood. We would like to acknowledge this support and thank Vanita Nayak Mukherjee for her encouragement.

A previous version of this report was peer reviewed by Nicole Haberland and Pertti J. Pelto. We are very grateful to them for their insightful reading of the report and their valuable comments and suggestions, most of which have been incorporated in this report.

Preparing this report was a team effort. We are grateful for research assistance to MA Jose, Shilpi Rampal and Komal Saxena. MA Jose and Komal Saxena helped us access the pertinent literature; Shilpi Rampal and Komal Saxena played a key role in analysing the textual data; Komal was also responsible for design issues and preparing the manuscript for publication. Jyoti Moodbidri's editorial contributions have been significant and we thank her for both her technical inputs and her meticulous attention to detail, which have made the report more readable and precise.

We would also like to acknowledge with thanks the contribution of our teams of young and enthusiastic interviewers who painstakingly collected the data, as well as our research assistants who did an excellent job 
of translating and coding the data. We would also like to record our appreciation of the support and kindness of the people in the villages and urban neighbourhoods in which we conducted our study, and specifically panchayat members and community leaders. While initially sceptical about the study, community members opened their homes to us and acknowledged the importance of this study for the health and development of future generations. Indeed, despite the sensitive issues covered, not a single study community refused our field teams entry. The trust and support of the people are gratefully acknowledged. Finally, and most importantly, we would like to thank the mothers and fathers from our six states who welcomed us, generously gave their time and shared so many intimate details of their lives with us. 


\section{Executive summary}

The Youth in India: Situation and Needs 2006-07 study included, along with a survey of youth in six states, in-depth interviews with mothers and fathers of youth in the same states. Mothers and fathers were selected purposively and were drawn from purposively selected villages and urban wards located within a 10 kilometre radius of those selected for the youth survey. A total of 412 parents were interviewed, including 209 mothers and 203 fathers. Interviews were wide-ranging and covered parental perspectives on their children's life, aspirations for their future and extent of communication with their children with special emphasis on communication about matters relating to the physical changes associated with puberty, sex, pregnancy and sexually transmitted infections/HIV. Interviews with most, but not all, parents covered topics related to parentchild communication.

While exceptions to the general pattern do exist, findings suggest, by and large, a regional divide in parentchild communication on non-sensitive matters. More parents in the northern states than in the southern states and, to a lesser extent, the western state of Maharashtra, described communication with their children as authoritarian. In the northern states for example, communication between parents and children was described as limited because of children's fears or shyness about communicating with their parents, and largely based on the day-to-day needs of the parent, child or household. While communication between mothers and children in these states was closer than that between fathers and children, it focused for the most part on the home and also reflected the day-to-day needs of the household or the young person. Nevertheless, both mothers and fathers emphasised that communication also comprised messages on the importance of education, guidance on appropriate behaviour, and the importance of maintaining the family's reputation. Relatively few mothers and fathers described their interactions as free or friendly.

While many features of communication, for example the focus on children's education and appropriate behaviour, also characterised parent-child communication in Andhra Pradesh and Tamil Nadu, and to a lesser extent, Maharashtra, differences were observed. Communication was, in many cases, described as more open and direct, with less evidence of the distance observed between parents and children than in the northern and western states, with several children described as being free to disagree with their parents and parent-child communication likened to that between friends.

Notwithstanding these differences in communication about non-sensitive topics, when it came to sensitive topics relating to sexual and reproductive health, including the physical changes associated with puberty, and those relating to sex, pregnancy and infection, regional patterns were less discernable. Although programmes, including the $\mathrm{RCH}-2$, have recognised the importance of parents in development outcomes of their children and interaction between parents and their adolescent children on these matters remained limited in all six states, and urban-rural differences were relatively narrow.

Discussion on the physical changes associated with puberty was gendered, both in terms of communication with daughters versus sons, as well as in terms of communication by the mother versus the father. For 
example, communication focused far more on the girl than the boy. For girls, it focused on the mechanics of menstruation - "use of the cloth" and dos and don'ts of appropriate behaviour during menstruation as a result of her new status as a mature person rather than on the meaning of menstruation and the menstrual cycle and its links with pregnancy. Many mothers reported discomfort stemming from shyness and embarrassment about discussing even menstruation with their daughters, many leaving it to other women in the family, most often grandmothers and aunts, to convey this and other information relating to sexual and reproductive health matters to children. A number of mothers specifically noted that girls were not provided with information about menstruation until it happened, and as a result, many described their daughters' fears and bewilderment about it when it occurred. Communication with sons, in contrast, was typically absent, with a few parents mentioning the growth of facial hair and voice change. Gender differences were also evident in terms of communication by the mother as opposed to the father. Fathers were more likely than mothers to have communicated with their sons about the physical changes associated with puberty, but the extent of their communication was typically limited. In contrast, fathers almost never communicated with their daughters on this issue, commenting rather that this type of information could only be conveyed by the mother or other female relatives.

While communication on the physical changes associated with puberty was clearly gendered, this was not so evident in parents' narratives about communication on such aspects of sexual and reproductive health as pregnancy and infection. Notwithstanding the fact that both mothers and fathers were typically reticent about providing their children with such information, findings point to a change among some parents towards a greater willingness to discuss sexual and reproductive health matters with their children, a change perhaps, resulting from their concerns about the consequences of HIV/AIDS. For example, in contrast to conventional indirect messages exhorting children to be good, not to get involved in wrong things, not to spoil the family's reputation and so on, the narratives of these parents indicate that they cautioned their children more directly, reporting messages designed to instil fear, most often about the links of 'bad' behaviour with HIV and its life-threatening consequences. Additionally, a few parents who reported communicating with their children on these matters were themselves misinformed and conveyed misconceptions to their children.

Both mothers and fathers, irrespective of region or urban-rural setting, described a range of factors that inhibited them from discussing the physical changes associated with puberty and/or sex, pregnancy and sexually transmitted infections/HIV with their children. Most often cited were cultural norms that made it unacceptable for parents and children to discuss sexual and reproductive health matters. Many of these parents reported for example, that parents in their setting did not discuss sex, pregnancy or infection with their children, and that young men and women, particularly young women, should not be informed about sex until marriage, and that once married, they would come to know about it automatically. Others suggested that in their cultures, children as young as the child in question (all aged 15 and above) were too young to be informed about these matters. A second leading factor inhibiting communication, also closely associated with cultural taboos, was discomfort and embarrassment both on the part of parents themselves and on the part of their children. In many ways, parents reported that they were too shy to speak to their children, and alternately, that their children were too shy to speak to them. While not an obstacle, several of these parents noted their children's preference for obtaining this information from the extended kin network, thereby 
reducing their need to communicate on these topics with their children. A third leading reason parents gave for their limited communication was their perception that youth today became aware of these matters on their own through interactions in the school setting, through television and books, through friends, and less often, through the more traditional providers of this information, that is, family elders, older siblings and/or sistersor brothers-in-law. A fourth factor, expressed by a few parents but perhaps underlying all of those described above, was the concern that communicating about matters relating to sex would be perceived by young people as a license to experiment with sex; in the words of one parent, "..it is like parents teaching that".

The kinds of obstacles to discussing sexual and reproductive health matters-largely sex, pregnancy and infection, but also, in several instances, the physical changes associated with puberty-described by mothers and fathers and by rural and urban parents were, on the whole, similar. Mothers were, however, considerably more likely than fathers to report discomfort and shyness experienced by themselves as well as their children, as an obstacle, and somewhat more likely than fathers to suggest that children came to know these matters on their own. Fathers were more likely, in contrast, to report fears that children would go astray if informed by their parents about sexual and reproductive health matters. Likewise, urban mothers and fathers were less likely than their rural counterparts to report that they were uncomfortable or shy about discussing these matters with their children; conversely, urban mothers and fathers were more likely than their rural counterparts to report that their children were shy or uncomfortable to discuss such matters with them.

Despite all of these misgivings, several parents acknowledged the need to provide children information on the physical changes associated with puberty, as well as information on such sexual and reproductive health matters as sex, pregnancy and/or infection. Wide differences were observed between fathers and mothers. Mothers were far more likely to adhere to traditional cultural norms about the provision of such information to their children than were fathers. Indeed, almost three times as many fathers as mothers favoured the provision of sexuality-related matters to their children. Urban-rural differences were much narrower; indeed, they were not observed at all among mothers.

Many parents spoke in generalities of the importance of conveying information on the physical changes associated with puberty and/or other sexual and reproductive health matters to their children, without necessarily identifying the preferred source of such information. However, a considerable number of fathers, and fewer mothers argued that the school was best suited to provide this education to their children. Gender differences among parents were far wider than were urban-rural differences. State-wise differences were also notable. Indeed, it was fathers of young people in the three states characterised by high levels of HIV/AIDS (Andhra Pradesh, Maharashtra and Tamil Nadu) who were most in favour of sexuality education in general and in the school setting in particular; in contrast, few fathers in the low HIV prevalence states of Bihar and Jharkhand expressed such a preference. State-wise patterns were not as clear among mothers; even so, half of those favouring school-based sexuality education came from a single state, Maharashtra. Clearly, both the HIV situation and deeply-entrenched cultural norms conditioned the priority that mothers and fathers placed on providing sexuality education to their children. Nevertheless, that a sizeable proportion of parents, particularly fathers and especially those from the high HIV prevalence states, approved of sexuality education, suggests that concerns about the threat posed by HIV/AIDS to their growing children, led them to question the traditional 
cultural taboos proscribing the communication of sexual and reproductive health matters, and acknowledge the need for sexuality education. This willingness to change (also observed in the findings reported in Chapter 3) and their recognition of the relevance of sexuality education in their children's lives, holds promise for engaging parents' support for efforts to promote the sexual and reproductive health of young people.

Three broad groups of suggestions were made to enable the transmission of information relating to sexual and reproductive health matters. Some parents argued that parents would not be able to communicate this information, and stressed the need for the school system to take on this task. A second group believed that such information should be transmitted by parents, and that parents themselves needed to be educated in what to say and how to convey messages. A third group maintained that they were prepared to discuss these matters with their children, but expected their children to raise the topic with them rather than initiating the discussion themselves.

\section{Recommendations for programmes}

The patterns of parent-child communication on sexuality-related matters observed among parents in all six states, irrespective of the state's level of development or the extent of gender equity characterising the state, clearly highlight the importance of efforts to encourage closer and more supportive communication between parents and young people. We have seen, for example, that the content of parent-child-and parentdaughter-communication is typically intended to ensure that young people conform to prevailing social, gender and relationship norms. Programmes are therefore urgently needed that orient both mothers and fathers, and that inform parents about effective parenting styles and the need for and importance of close communication with children, and, finally, enable them to question prevailing social, gender and relationship norms.

While acknowledged by relatively few parents, it is likely that parental inhibitions arise also because of their own lack of knowledge of sexual and reproductive health matters, and their perceived inability thus to respond to their children's questions. Findings suggest that even among those who did provide information to their children, this information was not always accurate. These findings call for adult sexuality education programmes that inform men and women about sex and reproductive processes, pregnancy and infection, reproductive rights, and more specifically, the physical changes associated with puberty.

It is clear that parents hold many misconceptions, for example, that girls should not be informed about menstruation until it happens or young men and women, particularly young women, about sex and reproduction until marriage, that youth will interpret any communication on matters relating to sexual life as a licence to experiment with sex, and that young people are well-informed about sexual matters through the media and friends. Programmes for parents need to dispel these misconceptions and highlight the need for and acceptability of providing their children this information themselves.

As mentioned above, most mothers agreed that girls need not be informed about menstruation until it happens. Thus, it is not surprising that many women described their daughters' first experience of menstruation as traumatic, characterised by tears, fears that their parents would be angry, and concerns 
that the blood signified their ill-health. Many women also described their communication with their daughters following the initiation of menstruation as defined by the mechanics rather than the meaning of menstruation- "how to use the cloth" and dos and don'ts (don't talk to boys, don't come inside the kitchen etc) associated with menstruation, rather than the menstrual cycle, and its links with pregnancy and reproduction. Efforts are needed that inform parents about the need for providing timely information to girls before and not after they start menstruating, and that age appropriate information is provided that explains the menstrual cycle and its links to pregnancy.

Efforts must also be made to reduce parental inhibitions about talking about the physical changes associated with puberty and/or sex with their children. Discomfort due to embarrassment and shyness were expressed by many parents - particularly mothers, but also fathers; they were also described as characterising their children's reluctance to communicate with their parents on these issues. Efforts are needed that break down inhibitions at both parent and child levels. Interventions that alternate between individual parent and child sessions and combined parent-child sessions would appear to be a promising approach whereby to reduce discomfort experienced by parents and children, respectively. Survey findings showed that about one in three young women and fewer than one in ten young men reported that they would like to obtain information on sensitive topics from their parents. At the same time, several parents suggested that they would be ready to discuss issues relating to the physical changes associated with puberty, and other sexual and reproductive health matters if their children initiated the discussion. While programmes are needed that focus on parents' life skills and sexuality education programmes should also build young people's skills and confidence and enable them to overcome their inhibitions in discussing sensitive and non-sensitive matters with their parents. Lessons may be drawn from programmes for young people—particularly for the school-going-conducted elsewhere that include activities or homework for young people to do with their parents that enable learning and at the same time provide an opening for parents to initiate discussion on sexual and reproductive health matters with their children.

Findings have reiterated the serious social proscriptions with puberty that fall on young women, and, to a lesser extent, young men, and that the content of communication from parents to children focuses on the importance of conforming to and perpetuating prevailing social, gender and relationship norms. Programmes for parents and for young people need to enable parents, as much as young people, to clarify values, to question traditional norms, including the social and gender-related constraints that limit young people from attaining their full potential; effective community mentors and local role models are needed that allay parents' concerns about allowing their children to deviate from traditional norms and behavioural expectations.

Findings have suggested the gendered nature of communication between parents and children. While content is limited, communication is most likely among mothers and daughters. To a more limited extent, communication is observed between fathers and sons, but in general, fathers rarely communicate with their children on sensitive matters. Programmes are needed that focus on men and boys: that involve fathers in communicating more effectively with their sons and daughters on sexual and reproductive health matters, and those that ensure that sons are not excluded from discussions about such sexual and reproductive health matters as the physical changes associated with puberty, sex, pregnancy and infection. In general, programmes 
must encourage greater openness and interaction between parents and children and enable the adoption of more gender-egalitarian child-rearing practices. While precedents are unfortunately unavailable, promising approaches through which to engage parents must be explored and may include such formal mechanisms as parent-teachers associations and other non-formal mechanisms such as those relying on community opinion leaders and community groups.

Many parents, even those who had not discussed sensitive matters with their children, agreed about the need for sexuality education for young people. Others, who did not so agree, reported that youth obtained this information on their own in school and through friends. Clearly, notwithstanding the furore created about India's Adolescence Education Programme and the need to provide life skills education to school-going youth, parents do indeed acknowledge their own reluctance to communicate on these matters with their children, and perceive the school as an acceptable setting from which to impart sexuality education to children. While enhancing close communication between parents and children is central for youth development, addressing norms and breaking down inhibitions may not show results in the shorter term; it is important therefore, that keeping parents' own preferences in mind, schools are equipped and empowered to communicate with young people on the physical changes associated with puberty, sex, pregnancy and sexually transmitted infections, and that the Adolescence Education Programme and similar efforts are widely implemented. The positive attitudes towards sexuality education held by some parents, particularly fathers, suggest that engaging parents, and particularly fathers of school-going children, may facilitate community acceptance for the promotion of school-based sexuality education programmes. Findings have suggested that several parents-mothers, much more than fathers-oppose sexuality education for their children, in or outside of schools. It is particularly important that programmes understand and dispel their fears and concerns and convince them of both the need for school and NGO programmes to impart this education to their children, and for them to communicate better with their sons and daughters on these matters.

\section{Recommendations for research}

Our study is one of the few studies that have explored the perspectives of parents with regard to communication about sexual and reproductive health matters. While it has presented many interesting insights, a number of issues clearly need further exploration.

First and foremost, quantitative research is required to complement the insights from our entirely qualitative study design. How parents perceive their communication with their children, the obstacles and misconceptions they face in informing their children about sensitive matters, and their preferences for doing so need to be documented.

Second, research elsewhere has shown that parents and children often have diverging perceptions about their communication on sensitive topics (Newcomer and Udry, 1985) and research is needed that will assess the extent to which this divergence is evident in India, and the effect of convergence or divergence in perceptions on youth behaviours in the sexual and reproductive health arenas. 
Third, research is needed that explores the links between close parent-child communication and the transition into sexual life, the extent of risk-taking and the extent of informed sexual and reproductive decision-making.

Finally, there is need to implement and test the effectiveness of interventions designed to improve parentchild communication and interaction.

\section{Conclusion}

There is enough evidence from around the world that parents matter, and that supportive communication between parents and children enables young people to make a safe and confident transition to adulthood. Our study, one of the first from India to probe parental perspectives, suggests that parents are indeed concerned about their children's transition into sexual life, but are constrained by traditional norms, lack of information and limited skills from communicating with and providing them the supportive environment needed to make this transition. It is important that efforts are initiated that enable parents to overcome these constraints. 



\section{CHAPTER 1}

\section{Introduction}

Parents, likely the most consistent influence in children's lives, are in a unique position to influence young people's health and personal development, and their transition to sexual life (World Health Organization, 2007). When the parent-child relationship is hierarchical and authoritarian, it can have an adverse influence both on how adolescents feel about themselves and the choices they make about behaviours that affect their health (Kirby, 2007; Whitaker and Miller, 2000). A growing body of research conducted with young people in developing country contexts has confirmed that parents can influence the sexual decision-making of their adolescent children (see for example, KumiKyereme et al., 2001; Zhang et al., 2007; Blum and Mmari, 2005; Mohammadi et al., 2007; Ngom, Magadi and Owuor, 2003; Li, Stanton and Feigelman, 2000; Bettinger et al., 2004; Roche, Ahmed and Blum, 2008). These findings are consistent with a considerably larger body of evidence from the US that has found that parentchild connectedness and communication plays an important role in delaying sexual initiation, reducing multiple partner relations and increasing condom use (Miller et al., 1998; Meschke, Bartholomae and Zentall, 2000; DiClemente et al., 2001; Hollander, 2007; Lederman, Chan and Roberst-Gray, 2004; Ryan et al., 2007; Aspy et al., 2007; Kirby et al., 1991; Whitaker et al., 1999).

Further, several studies in developing countries that have focused on the nature and influence of parent-child communication on sexual and reproductive health matters, have concluded that parent-child communication on these matters is uncommon (Biddlecom, Awusabo-Asare and Bankole, 2009; Kiragu et al., 2007; Joint United Nations Programme on HIV/AIDS (UNAIDS), 2008; Cui, Li. and Gao, 2001). Where it takes place, moreover, messages provided by parents on sexuality are usually ambiguous (for example, 'do not play with boys'; Luwaga, 2004).

In India, notwithstanding the recognition in policies and programmes of the need to actively engage parents in enabling adolescents to make safe and healthy transitions to adulthood (Ministry of Health and Family Welfare, 2006), evidence about parent-child interaction and communication, particularly with regard to sensitive matters such as the physical changes associated with puberty, sex, pregnancy and sexually transmitted infections/ HIV is sparse. Evidence that is currently available comes largely from the perspectives of young people rather than parents themselves and suggests that socialisation, for many, tends to be authoritarian-particularly for young women—and that communication between parents and both sons and daughters tends to be limited, particularly on sensitive personal matters (see for example, Shekhar et al., 2007; Abraham and Kumar, 1999; Mehra, Savithri and Coutinho, 2002; Alexander et al., 2006; International Institute for Population Sciences (IIPS) and Population Council, 2010), and that strong cultural taboos inhibit talking about sex (Lambert and Wood, 2005).

Evidence on parent-child communication on sexual and reproductive health matters from the 
perspectives of parents comes from a few small and unrepresentative studies (Soletti et al., 2009; Mahajan and Sharma, 2005; Garda and Alexander, 2009; Shetty, Kowli and Patil, n.d). These studies confirm that communication is limited and highlights a range of obstacles that may inhibit parents' ability or skill in communicating with their children on the physical changes associated with puberty. For example, village-level studies have identified parents' own lack of awareness (Soletti et al., 2009; Garda and Alexander, 2009) and their perception that their children were not at risk of HIV as key factors limiting communication (Soletti et al., 2009); other studies have noted parental discomfort and perceptions that informing their children about sexual matters would lead them to engage in sex (Shetty, Kowli and Patil, n.d; Mahajan and Sharma, 2005; Garda and Alexander, 2009).

For the first time, data are available from several states of India that shed light on socialisation and parent-youth interaction patterns from the perspectives of parents of young men and women as well as from young people themselves. These data allow us to explore the interaction between youth and their parents on sensitive sexual and reproductive health matters both from the perspective of youth themselves and of parents of youth. Perspectives of youth have been described in an earlier work and confirm the limited communication on such matters between parents and children (see IIPS and Population Council, 2010).

In this report we probe, from the perspectives of parents themselves, the extent and nature of communication with their children on sexual and reproductive health (SRH) matters, and the factors that inhibit parents from discussing these matters with their children. Sexual and reproductive health matters encompassed in this report cover the physical changes associated with puberty, as well as such matters as sex, pregnancy and sexually transmitted infections/HIV.

\section{Study setting}

Data are drawn from the Youth in India: Situation and Needs study, a sub-nationally representative study undertaken for the first time in India, of key transitions experienced by young people in six states of India (IIPS and Population Council, 2010). The study was conducted in both rural and urban settings of these states (Andhra Pradesh, Bihar, Jharkhand, Maharashtra, Rajasthan and Tamil Nadu), purposively selected to represent the different geographic and socio-cultural regions within the country. Together, these six states are home to almost two-fifths of India's population (Office of the Registrar General and Census Commissioner, 2001a). Distributions of the youth population in these states taken together by age, level of literacy, religion, caste and marital status were similar to those of the youth population nationally. Nonetheless, the six states lie at the extremes of the socio-economic and cultural spectrum of the country, reflecting, for the most part, the well-known regional diversity within the country in social, economic and demographic characteristics. Andhra Pradesh, Maharashtra and Tamil Nadu are among the more economically progressive states in the country, accounting for 7-13 percent each of the national Gross Domestic Product, while Bihar, Jharkhand and Rajasthan are among the lesser developed states, accounting for 2-4 percent each (Ministry of Statistics and Programme Implementation, 2008). Maharashtra and Tamil Nadu are among the most urbanised states, with over two-fifths of their populations living in urban areas. In contrast, Bihar, Jharkhand and Rajasthan are characterised by large rural populations, with just one-tenth to one-fifth of their populations living in urban areas (Office of 
the Registrar General and Census Commissioner, 2001b). Finally, differences are also evident in terms of kinship structure and gender relations: the three northern states represent settings in which family systems are particularly age- and gender-stratified, and women's agency particularly restricted, while Maharashtra and the two southern states represent settings in which relations are relatively more egalitarian and women have relatively more agency (Altekar, 1962).

\section{Methodology}

\section{Data}

The Youth Study comprised three phases: a pre-survey qualitative phase that included in-depth interviews with parents, a survey of youth, and post-survey in-depth interviews with selected survey respondents. Data presented in this paper are drawn from the in-depth interviews with parents. The survey (see IIPS and Population Council, 2010, for a description) focused on married and unmarried young women and unmarried young men aged 15-24 and, because of the paucity of married young men in the younger ages, married young men aged 15-29. A total of 50,848 young people were successfully interviewed from 174,037 households enumerated in the survey. The survey was conducted in three states (Jharkhand, Maharashtra and Tamil Nadu) in 2006-07 and three states (Andhra Pradesh, Bihar and Rajasthan) in 2007-08.

Prior to the survey of youth (Youth Survey), in 2005, in-depth interviews with mothers and fathers of youth in the above-mentioned categories were held in each state, including in rural and urban settings, in order to obtain the perspectives of this key but poorly studied gatekeeper group. Within each state, study sites were purposively selected to correspond with villages and urban wards selected for the Youth Survey. For the selection of rural sites, one or two villages were selected from each of the geographic divisions into which each state was divided. Further, the selected villages were required to be located at a distance of approximately 10 kilometres from a village selected for the Youth Survey, so that parental perspectives would be drawn from roughly the same socio-cultural areas as youth perspectives, yet would not affect the implementation of the Youth Survey in any way. For the selection of urban sites, one ward was selected from each of the three largest urban areas of the state, focusing on low income wards and making sure that the selected ward was similar to the one selected for the Youth Survey in terms of socio-economic conditions. In this way, five to six rural and three urban settings were selected in each state.

In each study location, attempts were made to interview one mother and one father, respectively, of unmarried and married young women and unmarried young men aged 15-24, and married young men aged 15-29, that is, a total of eight parents in each village or urban ward. Interviews focused on parental experiences with all his/her children in these age groups, enabling comparisons of parental perspectives on the socialisation of sons versus daughters. Parents were selected purposively, through key influentials (sarpanch or panchayat member, health care provider, school teacher or anganwadi worker, or a representative of a nongovernmental organisation working in the area) in each study village or urban ward. Only one parent from a selected household was eligible for interview. A snowball sampling method was used to identify eligible respondents.

Both the survey of youth and in-depth interviews with parents that preceded it inquired about several aspects of parent-youth communication. In the Youth Survey, communication was measured by whether 
parents and youth had discussed a number of topics, ranging from the non-sensitive (schooling, friends) to the sensitive (romantic relationships, body changes, sex, pregnancy and sexually transmitted infections/ HIV).

The in-depth interview with parents focused on three aspects of communication. Parents were first asked about communication with their children on general topics, what the main topics of discussion were, and how free and open the parent-child communication style was. They were also asked specifically about whether they had talked to their children about such sexual and reproductive health matters as the physical changes associated with puberty, as well as sex, pregnancy and sexually transmitted infections/HIV; the discussion focused not only on whether these topics had been discussed but also what aspects were discussed and, if communication was limited, the perceived reasons. We note that in general, more parents were willing to elaborate on their communication with their children on matters relating to physical changes associated with puberty rather than on matters relating to sex, pregnancy or sexually transmitted infections/HIV.

In each state, between 60 and 72 mothers and fathers were interviewed in depth, making for a total of 412 interviews across the six states, as seen in Table 1.1.

\section{Analysis}

A coding scheme was developed and transcripts were coded in ATLAS.ti, using this coding scheme. The coded blocks of text related to specific themes, for example, communication with children on general matters as well as the physical changes associated with puberty, sex, pregnancy and sexually transmitted infections/HIV; obstacles faced in, as well as reasons for non-communication, and so on. These blocks were analyzed to capture typical patterns.

In order to give an idea of the extent to which typical patterns were observed, we have provided counts of various response categories along with textual evidence. In addition, in view of the large numbers of in-depth interviews conducted in this study, we have opted to provide percentages throughout the report. These percentages enable regional and gender differences to become more clearly evident. However, we advise readers that percentages presented in this report may not be representative of the population at large and should be interpreted cautiously.

Textual evidence is provided from parents from as many of the states as feasible. We acknowledge that, as a result, quotes are somewhat repetitive at times but have opted to include them in order to underscore the extent of similarities in the

\section{Table 1.1}

Number of in-depth interviews conducted with parents, by state

\begin{tabular}{|l|c|c|c|c|}
\hline \multirow{2}{*}{ State } & \multicolumn{5}{|c|}{ Number of interviews conducted } \\
\cline { 2 - 6 } & Mothers & Fathers & Rural parents & Urban parents \\
\hline Bihar & 36 & 36 & 48 & 24 \\
\hline Jharkhand & 36 & 36 & 48 & 24 \\
\hline Rajasthan & 33 & 31 & 40 & 24 \\
\hline Maharashtra & 36 & 36 & 48 & 24 \\
Andhra Pradesh & 36 & 36 & 48 & 24 \\
Tamil Nadu & 32 & 28 & 37 & 23 \\
\hline Total & $\mathbf{2 0 9}$ & $\mathbf{2 0 3}$ & $\mathbf{2 6 9}$ & $\mathbf{1 4 3}$ \\
\hline
\end{tabular}


perspectives of parents from different settings on a particular issue.

Finally, because, as discussed above, the focus of parents' narratives lay more in the area of the physical changes associated with puberty rather than on other aspects of sexual and reproductive health, our analysis discusses communication relating to the physical changes associated with puberty, and that relating to sex, pregnancy or sexually transmitted infections/HIV separately.

\section{Characteristics of respondents}

A profile of the socio-demographic characteristics of mothers and fathers who participated in the study is presented in Table 1.2. Typically, mothers were aged 40-45 and fathers, 45-55. As expected, fathers were more likely, for the most part, than mothers to have ever attended school, and mothers from the two southern states were considerably more likely than those from the northern states to have done so. Almost all mothers in Bihar and Jharkhand (31 each) reported that they were not engaged in wage-earning activities at the time of the interview compared to considerably fewer mothers in the remaining four states (13-23). Most fathers were engaged in cultivation or agricultural labour (10-16 in five states, and three in Tamil Nadu) or in service, business or professional activities (7-11 in five states, and 13 in Tamil Nadu). Reflecting well-known disparities in fertility levels, mothers and fathers from the three northern states had about one more child, on average, than did their counterparts in the western and southern states (4.3-4.5 versus 3.0-3.5). Household size ranged from 4 to 6 among mothers and fathers in Tamil Nadu to 6 to 8 among those in the three northern states.

\section{Limitations}

We note an important limitation of our data. The way topics were covered differed across states, reflecting, in many instances, the respondent's willingness to discuss various topics and the interviewer's ability to draw out pertinent experiences from the respondent. Indeed, narratives show that in several instances, particularly with regard to communication on sensitive sexual and reproductive health matters, responses were monosyllabic or deviated from the question posed. We acknowledge that, as a result, narratives from some states are richer than from others; and that narratives on some topics are richer than on other topics.

\section{Structure of the report}

This report comprises five chapters aside from this introductory one. Chapter 2 explores the nature of parent-child communication on non-sensitive matters, and Chapter 3 focuses separately on parentchild communication about such sensitive issues as the physical changes associated with puberty on the one hand, and sex, pregnancy and sexually transmitted infections/HIV on the other, highlighting gender differences in communication, and describing the content of communication where it occurs. Chapter 4 explores the factors that inhibit parentchild communication on these sensitive topics as perceived by mothers and fathers, and Chapter 5 explores parental perspectives on informing young people about these matters. Chapter 6 provides the key findings of this study and offers recommendations for programmes and further research. 
Table 1.2

Socio-demographic characteristics of study participants

\begin{tabular}{|c|c|c|c|c|c|c|c|}
\hline & Bihar & Jharkhand & Rajasthan & Maharashtra & $\begin{array}{l}\text { Andhra } \\
\text { Pradesh }\end{array}$ & Tamil Nadu & Total \\
\hline \multicolumn{8}{|l|}{ Age (years, mean) } \\
\hline Mothers & 41.6 & 40.6 & 42.6 & 44.8 & 42.2 & 45.2 & 42.8 \\
\hline Fathers & 49.4 & 51.1 & 45.6 & 53.0 & 50.1 & 55 & 50.7 \\
\hline \multicolumn{8}{|l|}{ Education ( $\mathrm{N}$ and \%) } \\
\hline Mothers & $\begin{array}{r}12 \\
(33.3)\end{array}$ & $\begin{array}{r}14 \\
(38.9)\end{array}$ & $\begin{array}{r}16 \\
(48.5)\end{array}$ & $\begin{array}{r}19 \\
(52.8)\end{array}$ & $\begin{array}{r}21 \\
(58.3)\end{array}$ & $\begin{array}{r}29 \\
(90.6)\end{array}$ & $\begin{array}{r}111 \\
(56.0)\end{array}$ \\
\hline Fathers & $\begin{array}{r}20 \\
(55.6)\end{array}$ & $\begin{array}{r}27 \\
(75.0)\end{array}$ & $\begin{array}{r}19 \\
(61.3)\end{array}$ & $\begin{array}{r}22 \\
(61.1)\end{array}$ & $\begin{array}{r}26 \\
(72.2)\end{array}$ & $\begin{array}{r}24 \\
(85.7)\end{array}$ & $\begin{array}{r}138 \\
(67.5)\end{array}$ \\
\hline \multicolumn{8}{|c|}{ Mothers' occupation (N) } \\
\hline Cultivator & 2 & - & 3 & 1 & 1 & - & 7 \\
\hline Agricultural labour & - & - & 5 & - & 6 & 1 & 12 \\
\hline Service/employed & 1 & 1 & - & 5 & 2 & 2 & 11 \\
\hline Business & - & - & 2 & 1 & 2 & 1 & 6 \\
\hline Professional & - & 1 & - & 2 & 2 & 1 & 6 \\
\hline Skilled labour & 1 & 1 & 1 & - & 2 & - & 5 \\
\hline Unskilled labour & - & - & - & 1 & 7 & 3 & 11 \\
\hline Housewife & 31 & 31 & 17 & 19 & 13 & 23 & 134 \\
\hline Not indicated & 1 & 2 & 5 & 7 & 1 & 1 & 17 \\
\hline \multicolumn{8}{|c|}{ Fathers' occupation (N) } \\
\hline Cultivator & 7 & 7 & 10 & 10 & 11 & 2 & 47 \\
\hline Agricultural labour & 3 & 9 & 6 & 1 & 4 & 1 & 24 \\
\hline Service/employed & 2 & 7 & 4 & 5 & 3 & 6 & 27 \\
\hline Business & 3 & 1 & 3 & 1 & 3 & 6 & 17 \\
\hline Professional & 6 & 2 & 1 & 1 & 2 & 1 & 13 \\
\hline Skilled labour & 3 & 1 & 1 & 5 & 9 & 1 & 20 \\
\hline Not indicated & 2 & 3 & 5 & 7 & 3 & 4 & 24 \\
\hline Unskilled labour & 7 & 1 & - & 1 & 1 & - & 10 \\
\hline Retired & 3 & 5 & 1 & 5 & - & 7 & 21 \\
\hline \multicolumn{8}{|l|}{ Children (Mean) } \\
\hline Mothers & 4.3 & 4.5 & 4.5 & 3.3 & 3.5 & 3.0 & 3.9 \\
\hline Fathers & 4.4 & 4.5 & 4.0 & 3.5 & 3.4 & 3.4 & 3.9 \\
\hline \multicolumn{8}{|c|}{ Household size (Mean) } \\
\hline Mothers & 7.7 & 7.3 & 6.5 & 4.9 & 5.3 & 4.4 & 6.1 \\
\hline Fathers & 6.7 & 7.3 & 5.8 & 5.7 & 5.5 & 4.5 & 6.0 \\
\hline
\end{tabular}

Note: Age not provided for 2 fathers each in Bihar, Jharkhand and Maharashtra; 6 fathers in Rajasthan; 5 mothers in Jharkhand and Rajasthan, 2 mothers in Maharashtra, and one mother in Tamil Nadu.

Education of one father and 3 mothers in Andhra Pradesh not known. 


\section{CHAPTER 2}

\section{Parent-child communication on non-sensitive matters}

In the course of in-depth interviews, parents were probed about the extent and content of their communication with their children on non-sensitive matters. Parallel questions were posed to young men and women in the survey of youth described earlier. In this chapter, we focus on findings with regard to parents' perceptions about communication with their children on non-sensitive or general topics, and complement these findings with those obtained from youth themselves. (IIPS and Population Council, 2010)

The majority of interviews-192 of 209 interviews with mothers (92\%) and 181 of 203 interviews with fathers (89\%) - highlighted that communication on non-sensitive matters did occur, with little urban-rural variation. Communication centred on the home, the family and daily life, and, if illness occurred, health care, and parents recognised, albeit in different ways, the important role they played in socialising their children and in transmitting norms and values to them. Several narratives highlight this recognition, for example, "We should know what is going on in the child's heart." (Mother, Rajasthan, rural, aged 50 years, Class 4) and "If parents don't support their children, then there is no meaning in the child's life." (Father, Maharashtra, rural, aged 42 years, no education). In contrast, a single question was posed in the survey to youth that related to general communication: the extent to which youth had discussed schooling issues with their parents. Findings suggest that just 56-67 percent of young men and women had discussed such issues with their mother or father (IIPS and Population Council, 2010).

Regional differences were apparent as suggested in Table 2.1 and correspond with the greater age- and gender-stratified kinship systems of the north and the relatively more egalitarian systems prevailing in the south (see, for example, Altekar, 1962). In general, communication between parents and children appeared to be more egalitarian in the two southern states, Andhra Pradesh and Tamil Nadu, than in the remaining states. In contrast, communication between parents-especially fathers-and children, was more hierarchical in the three northern states, namely Bihar, Jharkhand and Rajasthan, with communication with fathers, particularly distant and authoritarian. Communication patterns reported by parents in the western state of Maharashtra lay somewhere in between these two patterns. A similar pattern was also evident from the reports of youth with regard to communication with their parents about schooling. Indeed, young women in Maharashtra and the southern states were more likely than their northern counterparts to have discussed schooling issues with their father and mother (61-63\% versus 38-53\% with father; $68-75 \%$ versus $39-59 \%$ with mother; IIPS and Population Council, 2010).

\section{Parent-child communication in Bihar, Jharkhand and Rajasthan: Authoritarian}

Narratives of parents from the three northern states underscore a traditional hierarchical and authoritarian 
communication style. In particular, a number of mothers and fathers from the three northern states who talked about communicating with their children on general matters-nine percent each of the 93 mothers and 91 fathers- directly reported that their children feared or were shy to speak in their presence, and many others so implied (Table 2.1).

While most of these parents suggested that it was the daughter who was afraid or shy to speak in front of her parents, particularly the father, several did imply that sons were also likely to refrain from communicating with their father and, less often, their mother as well. For example, the following responses were obtained from parents when questioned about their relationship with their children:

As she is approaching adulthood, she is becoming conscious. Girls hesitate to talk frankly as they approach this age. [Father, Rajasthan, urban, aged 43 years, Class 10]

Girls generally don't talk to their fathers, and Lakshmi is scared to say anything to me.

[Mother, Rajasthan, rural, aged 48 years, Class 4]

He feels shy. [Mother, Bihar, rural, aged 36 years, no education]

He doesn't talk much because he is the eldest son and feels very shy of us. Sangeeta also doesn't speak much. She also feels shy. They are all kids. [Mother, Jharkhand, rural, aged 35 years, Class 2]

No. They don't talk openly with me. They are scared of me. [Father, Bihar, rural, aged 53 years, no education]

He feels shy to talk to me. She talks to her mother, but she only asks me about food etc. [Father, Rajasthan, rural, aged 47 years, Educational attainment level not available]
Both my sons and daughters are scared to talk to me. [Father, Jharkhand, urban, aged 45 years, graduate]

Narratives from mothers also confirm the distant relationship between their husband and their son, as reported by one mother:

He (son) can express his wish to eat or get something but not otherwise. If he is allowed to speak openly today, he might feel that he can ask anything (including about sexual matters) tomorrow. So, he (father) doesn't let him talk unnecessarily and maintains a distance. [Mother, Rajasthan, urban, aged 45 years, no education]

Mothers typically reported a closer relationship with their children, especially their daughters. Indeed, a few mothers and fathers from these three states reported that if their son or daughter required something, they would not convey their request directly to their father but would do so through their mother. In that sense, communication was somewhat more relaxed with the mother than with the father. For example:

Whatever she wants to say, she says it to her mother as, 'Please get me this or that thing from Papaji.' For example, if she needs copies (notebooks), paper, medicines, etc. she tells her mother to ask me to get them. She does not speak to me directly. [Father, Bihar, rural, aged 50 years, no education]

For example, when his bicycle needs repair, he tells me to ask his father for money to repair the bicycle. [Mother, Jharkhand, rural, aged 37 years, Educational attainment level not available]

As far as the content of communication is concerned, there is some evidence that communication with both fathers and mothers in these states was confined, in large part, to 


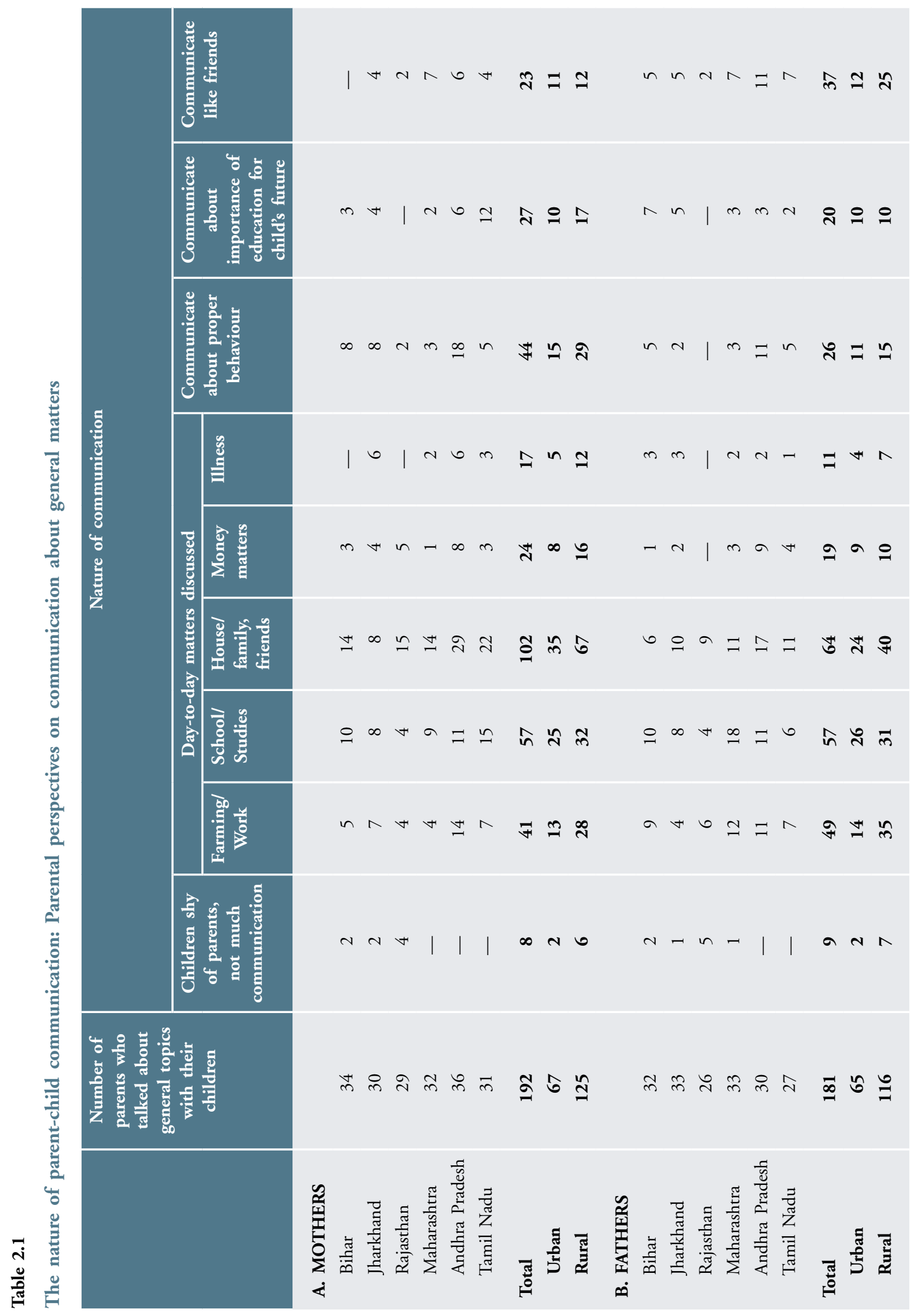


day-to-day matters. For example, of the 91 fathers who discussed the nature of overall communication with their children, topics reported included farming and work needs (19), school-related issues (22), home and family (25), money matters (3) and health (6) (Table 2.1, Panel B). Narratives from fathers suggest the following:

We talk about our family and house, about expenses and how these expenses can be managed. We talk about any problem in our house and how we are handling it. [Father, Bihar, rural, aged 48 years, no education]

If she has fever or a headache, then she would have to tell me, right? [Father, Bihar, rural, aged 55 years, Class 3]

Yes. We talk about things like putting the crops under the sun and other household work. [Mother, Bihar, rural, aged 35 years, no education]

Normal discussion... our problems and good things, farming matters, etc. We discuss how this and that work should be done. [Mother, Jharkhand, rural, aged 40 years, no education]

Why won't they talk? They say, 'Papa, give us so much (referring to the amount requested) money; we have to pay fees.' [Father, Jharkhand, rural, aged 40 years, Class 10]

She (daughter) asks me, 'Shall I make a vegetable? Shall I make roti? Shall I cut wood?' She also talks about other household work. [Father, Rajasthan, rural, aged 55 years, no education]

Even so, relatively few parents in this region identified their communication with their children as free and friendly: six of the 93 mothers (6\%), and 12 of the 91 fathers (13\%).
It is very good. I'm their father but I talk to them like a friend would about everything. [Father, Bihar, urban, aged 44 years, graduate] Yes. She (married daughter) used to joke in the family a lot... She used to laugh and talk freely with her father too. [Mother, Jharkhand, urban, aged 35, no education].

She talks to me like a friend. She does not think she is my mother', and I don't think 'she is my daughter.' We talk like this; we have a lot of fun. [Mother, Rajasthan, rural, aged 50 years, Class 4]

Narratives from mothers also suggest that communication between mothers and children in the three northern states often focused on day-today matters, as in the case of communication with fathers. Of the 93 mothers who discussed general communication in in-depth interviews, leading topics discussed included work and farming needs (16), schooling needs (22), home and family (37), money matters (12) and health (6) (Table 2.1, Panel A). For example:

Things like... they (daughters) ask me to buy them new clothes; one (of them) might say, I want this (a particular) type of clothes', and the other might say, 'I want that (another) kind of clothes.' Then I have to tell them, 'From where will your father get so much money to buy all these clothes for you?' [Mother, Bihar, rural, aged 35 years, no education]

When he needs a copy (notebook) or something... like a pen, or clothes, he asks me for money. [Mother, Bihar, rural, aged 35 years, no education]

Communication by parents also focused on behavioural norms. As shown below, many mothers-notably those from Bihar and Jharkhandreported conveying to their daughters, norms of 
femininity and how girls should behave with adults in the household as well as with their future in-laws. For example:

She is given a good education, told how to live properly in the house, how to speak properly to her father, grandfather etc (male family members) as well as with her grandmother (dadi or father's mother), aunt (chachi or wife of father's brother) etc (female family members). Also about stitching, knitting, etc. [Mother, Bihar, rural, aged 42 years, Class 8]

I would tell her what she should eat and how she should behave after she gets married and starts living in her in-law' house with her husband. [Mother, Bihar, rural, aged 35 years, no education]

I talk about good things and give moral lessons. What else? 'My child, do (it) this way or that way.' All this (instructing) and what else...? [Mother, Jharkhand, rural, aged 30 years, Class 3]

Yes. When she gets married, she should adjust satisfactorily with everyone in her in-laws' house. She should live properly; even if she has to study, she should find an appropriate time to study, so that she can keep her in-laws and her husband happy. [Mother, Jharkhand, rural, aged 41 years, Educational attainment level not available]

Communication with sons about appropriate behaviour was, in contrast, less frequently discussed, but when discussed, it was much more likely to be conveyed in terms of making a name for himself and upholding the family's reputation and social standing. For example:

(I discuss with him) in the same manner in which the society (people) normally discusses. (About) the manner in which one carries oneself and the manner in which one talks in the society. [Father, Bihar, rural, aged 38 years, no education]

A small but significant number of parents in these states suggested that in their conversations with their children, they conveyed the importance of education for their children's future and, in this sense, went beyond the discussion of day-to-day matters. Indeed, as indicated in Panels A and B of Table 3.1, respectively, seven of the 93 mothers $(8 \%)$ and 12 of the 91 fathers (13\%) reported that they had spoken with their children about their interest in their child's education or other aspects of well-being. A few parents reported discussing their children's future with them, or spending time with them resolving schoolwork difficulties, or just talking together as a family. For example, while discussing communication and interaction with children, these parents reported as follows $(\mathrm{I}=$ interviewer; $\mathrm{R}$ = respondent):

About work, about studies; that she should study properly. We talk about stitching, knitting, about food, about everything. [Mother, Jharkhand, rural, aged 41 years, Educational attainment level not available]

I: In those 1-2 hours, what do you talk about with your son?

R: I generally ask him how his studies are going on, whether he is studying properly. I tell him to study properly and do some work so that he makes a good name in the village; that he should not destroy the reputation of his family because his parents are spending a lot on his education. [Mother, Jharkhand, rural, aged 50 years, no education]

(We talk) about education, jobs, farming, about their future, etc. [Father, Bihar, rural, aged 40 years, Class 9] 
I tell her how she should do things and that intelligent people live life properly. I try to make her understand these things. Every day, I spend 10 or 15 minutes with her. We sit together in the evenings... like after the dinner is cooked, I sit along with my children and we talk with one another. [Father, Bihar, rural, aged 42 years, Class 9].

It is my routine to get an update on her studies every night. If she has any problems in her studies or if there is any other difficulty, I leave all my work and solve her problem. [Father, Bihar, rural, aged 45 years, graduate]

I always say that he should study well because education is a precious jewel. [Father, Jharkhand, rural, aged 44 years, Class 2]

\section{Parent-child communication in Andhra} Pradesh, Maharashtra and Tamil Nadu:

\section{Less authoritarian}

In contrast to the authoritarian parent-child communication style observed above, communication between parents and children, including fathers and daughters in Andhra Pradesh and Tamil Nadu, and to a somewhat lesser extent in Maharashtra, was characterised by greater directness and openness. Young people were rarely described as fearing a parent - not a single mother, and just one father (from Maharashtra), reported that their son or daughter feared or was shy of their father or that they made requests to their father through their mother.

Indeed in several narratives, parents reported that their son or daughter openly disagreed with them on occasion, and discussed their problems with both parents. Among parents who expressed their views on communication on general matters, 10 of the 67 mothers $(15 \%)$ and 18 of the 57 fathers
(32\%) from the southern states and seven each of the 32 mothers (22\%) and 33 fathers (21\%) from Maharashtra, likened their communication with their children as that between friends or highlighted that communication centred around their children's education and wellbeing (Table 2.1, Panels A and B, respectively). For example:

He talks to us if he has problems; (to) me more than to his mother. (My daughter) also consults me more, not so much her mother. [Father, Andhra Pradesh, rural, aged 50 years, no education]

My daughter tells me more than my wife does... Parents should mingle with them (children) and treat them as friends, and give advice in ways they will listen to. [Father, Andhra Pradesh, rural, aged 45 years, Class 5]

We talk like friends. (Parents and children) should talk like friends. [Mother, Andhra Pradesh, rural, aged 43 years, Class 9]

We talk about family matters, village matters, political matters and so on. We talk like brothers. [Father, Andhra Pradesh, rural, aged 48 years, Class 5]

(If Sasikala has a problem), she informs her mother and also informs me. She discusses with both of us... Sometimes she listens to us and sometimes she even scolds us. [Father, Tamil Nadu, rural, aged 44 years, Class 9]

He asks me about the actor Kamal's films and we talk to each other about movies. He tells me about his friends and we talk to each other like friends. [Father, Tamil Nadu, rural, aged 57 years, postgraduate]

If (she feels) what I say is correct, she listens, and if (she feels) it is wrong, then she says that it is 
wrong. If I tell her that she should behave like this (in a particular way), would she not listen? [Father, Tamil Nadu, rural, aged 49 years, Class 5]

After coming from school, she spends the evenings with me only. We talk about all her school subjects (vishayangal) and household matters too. [Mother, Tamil Nadu, urban, aged 42 years, post graduate]

Education was clearly a concern for many mothers, and somewhat fewer fathers, irrespective of their urban-rural residence or own educational background. For example, in the two southern states, 18 of the 67 mothers (27\%) discussed how they emphasised education for their children, compared to five of the 57 fathers (9\%); in Maharashtra, somewhat fewer parents (two or $6 \%$ of the 32 mothers and three or $9 \%$ of the 33 fathers) so reported (Table 2.1, Panels A and B, respectively). These parents described discussing with their sons and daughters the value of education for their children's future, motivating them to spend more time studying, and helping them with their studies:

I have told them from the time they were very small that education is very important and it is a ladder to success; that education can help them to achieve their goal and become someone in life. I have told them to study well in time; the children are studying and playing too. I have told them that they can go out to play after finishing their studies; when they come home, the first thing they must do is their studies, then any other work.

[Mother, Maharashtra, urban, aged 38 years, Educational attainment level not available] When my children and I are together, I ask them how they have fared in their studies throughout the day. Did they 'by heart' (memorise) the spellings? Did they read newspapers? Or did they do any other work? We discuss all such things. [Mother, Maharashtra, urban, aged 46 years, graduate]

They are good. We talk to each other. We talk about what is taught in school, what the teacher said etc. I also teach him how he should work in future. [Father, Maharashtra, urban, aged 44 years, Class 7]

They ask about matters concerning education. I ask them about their interest in studies. I tell them it is good to pursue their interests. [Father, Andhra Pradesh, urban, aged 50 years, Class 12]

Both of them talk about studies. They talk about their school, friends and how they spend their time in a jolly way. They talk freely. [Mother, Tamil Nadu, rural, aged 40 years, Class 12] Yes. I have told him that he has chances to go to USA to pursue his MS. I have told him that I would get him all the necessary applications. He says that if he too goes abroad there will be no one to take care of us. We keep telling him that if he studies well it will be better for his future career. [Father, Tamil Nadu, urban, aged 56 years, Class 10]

Parents in these states, like those in the northern states, described communicating with their children about appropriate norms of behaviour: 23 of the 67 mothers (34\%) and 16 of the 57 fathers (28\%) from the two southern states and three (9\%) each of the 32 mothers and 33 fathers from Maharashtra (Table 2.1, Panels A and B, respectively). Unlike in the northern states, however, very few narratives from these states focused on exhorting daughters to behave modestly in their marital homes; rather, discussions on behaviour for both daughters and sons-as opposed to discussion with just sons observed in the 
northern states-focused on the need to maintain the family's reputation. For example:

I ask them to lead a good life. No one should talk about us badly and no one should tell me that my children are bad. So I keep telling them that they should earn a good name and not make mistakes. If they make mistakes, I warn them. [Mother, Tamil Nadu, rural, aged 45 years, Class 6]

I advise them that girls should be treated as sisters and they should not tease them. I advise them to study well and earn a good name. I tell them that if they study well their future will be bright. I tell them that they should be seen (by others) to be making a good living. I advise them to respect their elders, not to scold others, and to be good. They listen to what I say. [Mother, Tamil Nadu, rural, aged 40 years, Class 12]

I have told him only one thing. That is the first and last. I have told him that he should get a good name to get ahead in life. [Father, Andhra Pradesh, urban, aged 54 years, Class 9]

Yes. We tell them how to behave with elders. We tell them how to speak with elders, how to respect them and all that. [Mother, Andhra Pradesh, urban, aged 35 years, Class 5]

My children have no bad habits. I tell them not to speak ill about others, not to tell lies and not to steal. [Mother, Andhra Pradesh, rural, aged 43 years, Class 9]

I have told him to treat all girl classmates well and not to do anything wrong. [Father, Andhra Pradesh, rural, aged 48 years, Class 5]

\section{Summary}

The majority of parents had discussed general or non-sensitive topics with their sons and daughters.
Topics that parents communicated with their children ranged from those pertaining to the dayto-day needs of the parents, child or household, to the importance of education, appropriate behaviours for sons and daughters, and current affairs (community matters, politics, movies etc). The style of communication ranged, moreover, from distant and intimidating to free and friendly. Findings were also suggestive of differences in parental communication with sons versus daughters. For example, more parents suggested that it was the daughter rather than the son who was afraid or shy to speak in their presence, and particularly in their father's presence; at the same time, mothers typically reported a closer relationship with their children, especially their daughters. With regard to messages conveyed, too, differences were observed. Most notably, while behavioural norms were transmitted to both sons and daughters, the focus for sons was on achievement and making a name for themselves and the family, while the focus for daughters was on appropriate feminine behaviour.

While exceptions to the general pattern do exist, findings suggest, by and large, a regional divide in parent-child communication. Communication was characterised as more authoritarian in the northern states, and less so in the southern states, with the western state of Maharashtra lying somewhere in between. In the northern states for example, communication between fathers and childrenparticularly fathers and daughters-was described as limited because of children's fears or shyness about communicating with their parents or father, and was largely based on the day-to-day needs of the parent, child or household. While communication between mothers and children in these states was closer than that between fathers and children, it focused for the most part on the home and also reflected the dayto-day needs of the household or the young person. Nevertheless, both mothers and fathers emphasised 
that communication also comprised messages on the importance of education, guidance on appropriate behaviour, and the importance of maintaining the family's reputation. Relatively few mothers and fathers described their interactions as free or friendly.

While many features of communication, for example the focus on children's education and appropriate behaviour, also characterised parentchild communication in Andhra Pradesh and Tamil Nadu, differences were observed. Communication was, in many cases, described as more open and direct, with less evidence of the distance observed between parents and children than in the northern states, with several children described as being free to disagree with their parents and parent-child communication likened to that between friends. Parent-child communication patterns in Maharashtra had features resembling both those in the northern and southern states. While communication was most often described as relating to day-to-day matters, a larger number of parents described communication as free and friendly. 


\section{CHAPTER 3}

\section{Communication about sexual and reproductive health matters}

In this chapter, we present findings on parents' perspectives about communicating with their children on sensitive topics, notably the physical changes associated with puberty on the one hand, and such sexual and reproductive health matters as sex, pregnancy and infection, on the other. Findings focus on whether these issues were discussed and the messages communicated. For the most part, when it comes to communication about such sensitive matters, the regional divide observed in communication on general issues was no longer observed; communication with their children was described as limited by both mothers and fathers in all six states.

Findings of the Youth Survey highlight that few youth had discussed the physical changes associated with puberty with their father (6-7\%), and while few young men had discussed these issues with their mother (5\%), far more young women had done so $(77 \%)$; presumably reflecting the discussion between mothers and daughters on menstruation (IIPS and Population Council, 2010). Further, the regional divide was muted among young men; among young women, however, somewhat larger proportions of those from Maharashtra and the southern states had discussed matters relating to the physical changes associated with puberty with their father $(5-11 \%$ versus $1-2 \%)$ and mother $(71-84 \%$ versus $60-74 \%)$

\section{Parents' perspectives on communication about the physical changes associated with puberty}

In-depth interviews with parents, by and large, corroborate young people's reports about communication on the physical changes associated with puberty. Gender differences are apparent: not only did the perspectives of mothers differ from those of fathers in many respects, but also, parents' reports about communication with their daughters (Table 3.1) differed from their reports of communication with their sons (Table 3.2).

Discussion of communication with daughters about the physical changes associated with puberty focused exclusively on menstruation; of the 145 mothers who reported, in the course of the interview, that they had discussed matters relating to the physical changes associated with puberty with their daughter, 59 percent (86) said that they had talked about menstruation (Table 3.1, Panel A). As expected, while 69 percent of urban mothers so reported (35 of 51), fewer rural mothers (54\% or 51 of 94) had done so. More than one-quarter of mothers who reported having discussed these changes, ( $28 \%$ or 41 of 145$)$ specifically reported that they had done so when their daughter started menstruating. Several described how unaware their daughter was at the time she started menstruating: 
She was crying. She said there was blood on her stomach. [Mother, Bihar, rural, aged 30 years, no education]

She said, 'See mother. What is this red mark that has come on my clothes?' I told her that she has started menstruating. I also taught her to use folded cloth with the help of a cloth-string during menstruation. [Mother, Jharkhand, rural, aged 40 years, Educational attainment level not available]

No. When she attained puberty, she told me that her underwear had become red. [Mother, Andhra Pradesh, rural, aged 49 years, no education]

Narratives suggest that communication about menstruation was largely restricted to how to protect oneself ("how to use the cloth") and keep clean during menstruation on the one hand, and the dos and don'ts relating to behaviour during menstruation on the other.

I told my elder daughter when she grew up, how to use the cloth, make it stay properly. [Mother, Bihar, rural, aged 42 years, no education]

Yes. When she had her first menstrual period, she told me about it. Then I told her that this happens with every female and taught her how to use clean cloth when she has her periods.

[Mother, Jharkhand, urban, aged 42 years, no education]

Yes. I told her about menstruation time and the use of cloth; what she should do when she has her period; how to dress up and everything regarding that. [Mother, Rajasthan, urban, aged 35 years, Class 6]

Yes. I told her. I told her after she had her menstruation - how to use (sanitary) pads and how to maintain hygiene. Who else could tell her? There was no other person who could give her this information. I had to tell her. [Mother, Maharashtra, urban, aged 45 years, Class 9]

(I) arranged for her bath and told her to take her bath properly. I told her that this happens to every girl. [Mother, Andhra Pradesh, rural, aged 30 years, Class 4]

Do's and don'ts typically focused on staying out of the kitchen and observing "good" behaviour. As the quotes below suggest, "good" behaviour largely implied staying away from boys, not speaking freely in general, and not going outside of the home, if avoidable:

I told her: 'Now you have grown up. You should be mature. You shouldn't talk to anyone like that (freely/openly), and you should behave properly.' Well, that's all. [Mother, Bihar, rural, aged 42 years, Class 4]

Yes. When she first had her period, I explained to her that she should not enter the kitchen or touch the food or water... I thought: who would explain (these) things to her if not me? So I told her about all this, and asked her not to worry but stay away from the kitchen for four days. [Mother, Rajasthan, urban, aged 45 years, Class 5]

Yes. I gave (her) information about it (menstruation): 'Now you have grown up. Do not stay outside (the home) for a long time. People should not call us (bad) names.' I have told her that we should behave in a good manner. [Mother, Maharashtra, urban, aged 42 years, no education]

I told her not to go here and there (outside the home) and not to play like before. [Mother, Andhra Pradesh, rural, aged 45 years, no education]

We told her how she should sit, what she should and should not eat; (that she) should sit in a 


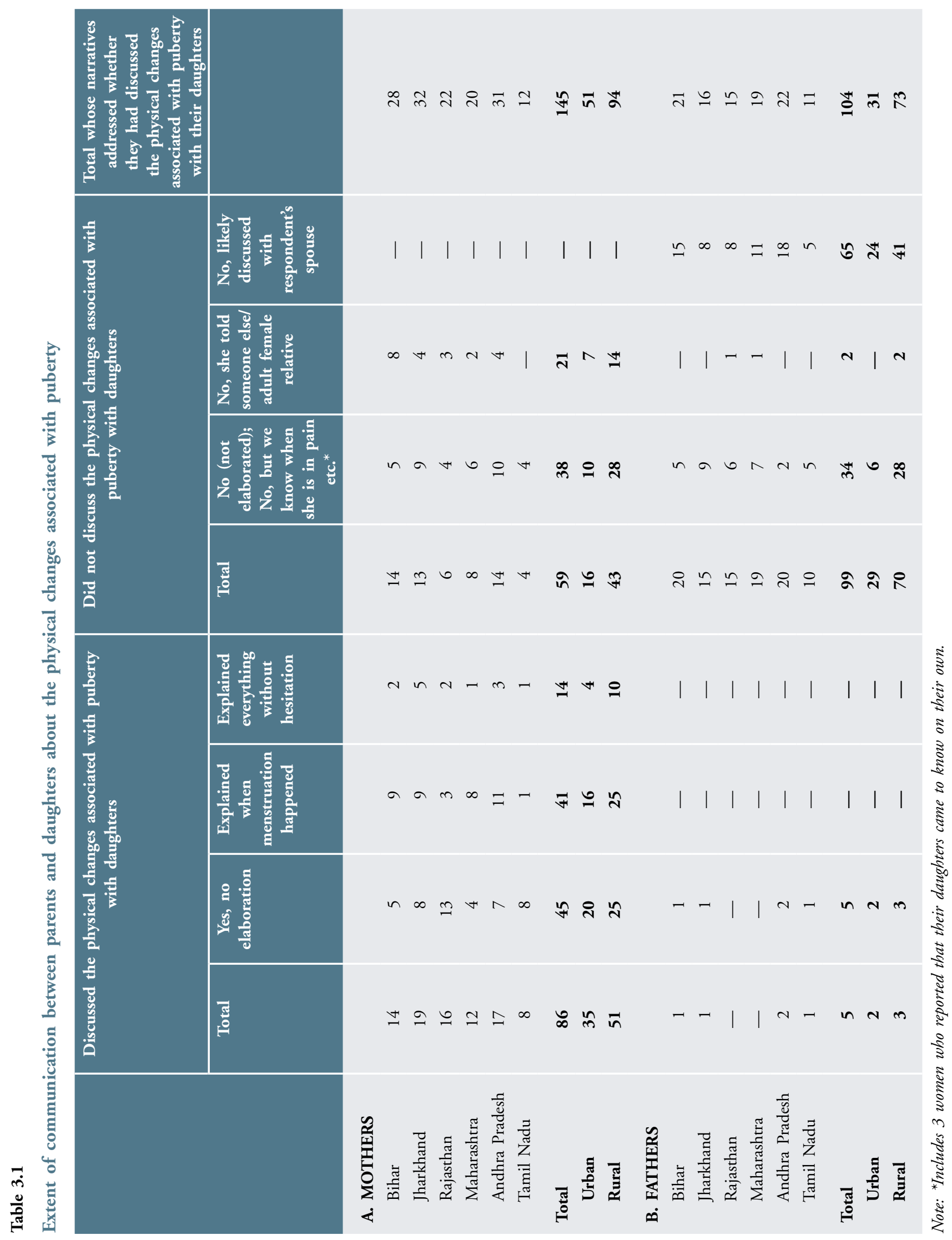


corner and not come out in the presence of boys.

This is the custom to be followed by ladies, and they should behave like that. She should not show herself to boys for a week or ten days and should not touch anything. (I) told her that this (menstruation) was expected (to happen).

[Mother, Andhra Pradesh, urban, aged 50 years, no education]

Even so, some 14 of the 86 women (16\%) who had discussed menstruation with their daughters reported that they had explained menstruation directly to their daughters without fear or hesitation; almost all these mothers too seem to have done so after menstruation had occurred (Table 3.1, Panel A). Unfortunately, none of the narratives describe the content of their communication; simply that they were not embarrassed and spoke openly to their daughters:

I told her that she has started her menstrual period. I also taught her to use folded cloth with the help of a cloth-string during menstruation.... No; I did not feel any hesitation. Who else could tell her about it? There was no other female in the family at that time. [Mother, Jharkhand, urban, aged 40 years, Educational attainment level not available]

I told them (daughters) about menstruation, how it happens, what happens, what care they should take during menstruation etc. I gave them some information about it. Yes, I told them without any hesitation. [Mother, Maharashtra, rural, aged 50 years, Class 11]

Yes. When she had her period for the first time, she got very scared. Then I told her that when girls grow up, this happens. All girls get this (periods). Even I get it. And now, it will happen every month. Then immediately I bought (sanitary) pads from a shop, and then she understood. Afterwards, she explained it to her younger sister as well. [Mother, Bihar, urban, aged 50 years, no education] Everything; everything. She told me everything. I explained to her the way a mother explains to a daughter. That's how a mother should tell her daughter. [Mother, Jharkhand, urban, aged 48 years, Class 9]

Yes. I told her about menstruation time and the use of cloth; what she should do when she has her period, how she should dress up and everything regarding that. [Mother, Rajasthan, urban, aged 35 years, Class 6]

She has not talked as such. At the time of her menstrual period, she asks me to get 'Whisper' (sanitary napkins) and I get it for her. When she has menstrual cramps (stomach pain), I get medicine for her. [Mother, Tamil Nadu, urban, aged 37 years, Class 4]

Panel A of Table 3.1 also indicates that a total of 59 of the 145 mothers (41\%) comprising 43 of the $94(46 \%)$ rural mothers and 16 of the 51 (31\%) urban mothers, reported that they had not communicated with their daughters about the physical changes associated with puberty. Of these 59 mothers, 38 (64\%) reported that if they observed that their daughter was likely having menstrual cramps, they helped her cope with menstrual discomfort, but had never had a direct discussion about menstruation with her. At the same time, 21 women reported that relevant information was conveyed to their daughter by her grandmother, aunt or other adult female relative. As many as 17 of these 21 women (81\%) were from the northern and western states, and 14 (67\%) were from rural settings. 
Mothers responded as follows:

No, she has not told me about it; she used to feel shy. She tells her aunt (chachi) everything openly; she does not tell me anything.... She has very friendly relations with her aunt (chachi), so she tells her and asks her everything. She may have told her (aunt). [Mother, Bihar, rural, aged 50 years, no education]

Yes; she did ask, but not me. She asked her grandmother and her grandmother told me about it. I did not tell her anything. Her grandmother told her everything about her periods. She feels shy with me; with her grandmother she is more open and free. She spends more time with her grandmother and is more attached to her. That is why she told her grandmother about it... [Mother, Bihar, urban, aged 32 years, postgraduate]

She did not share it with me but she shared this matter with her aunt (chachi). [Mother, Jharkhand, rural, aged 45 years, no education]

My mother-in-law was there when she (my daughter) started menstruating; she (mother-inlaw) is the one who explained it to her.

I never told her (daughter) and she never

asked. [Mother, Rajasthan, rural, aged 45 years, Class 5]

I did not tell my daughter anything. The first time she got her menstrual period, she had a stain on her dress. She told her friend to see what had happened to her... She (her friend) told her to show it to me and that I would explain it to her. My daughter said to her friend, 'How can I tell my mother? I don't know what has happened to me. My mother will get angry and shout at me.' [Mother, Maharashtra, urban, aged 45 years, Educational attainment level not available]
Communication between fathers and their daughters on the physical changes associated with puberty was much more limited (Table 3.1, Panel B). Indeed, just five (two urban and three rural fathers) of the 104 fathers who addressed the topic (5\%) during the interview, reported that they had discussed these matters with their daughter. As in the case of most mothers, none of these fathers described the content of their discussions. The remaining 99 fathers (95\%) said that they had not discussed these matters with their daughter. As many as 65 of these fathers (63\% or 65 of 104) reported that it was likely their wife had spoken to their daughters about these issues; a larger proportion of urban than rural fathers so reported-24 of the 31 urban fathers (77\%) and 41 of the 73 rural fathers (56\%). In addition, 34 fathers (33\%) reported that they had not discussed the issue with their daughter, but had supported her if she was in pain or discomfort during her periods by bringing her medicines or taking her to the doctor; a larger proportion of rural than urban fathers so reported: 28 of the 73 rural fathers $(38 \%)$ and six of the 31 urban fathers (19\%). Two fathers reported that their daughter had discussed these issues with someone else, and four perceived that their daughter was well-informed on her own and did not need to discuss these matters. For example, when asked who their daughter consulted when she had a physical problem, fathers responded thus:

She tells her mother to get her medicines... No; I will not talk to her. I can get medicines. [Father, Bihar, rural, aged 45 years, no education]

When she wants cloth (during menstruation), she says so; she tells her mother, and her mother tells me. [Father, Jharkhand, rural, aged 60 years, no education]

Communication with sons about the physical changes associated with puberty was even more 
Table 3.2

Extent of communication between parents and sons about the physical changes associated with puberty
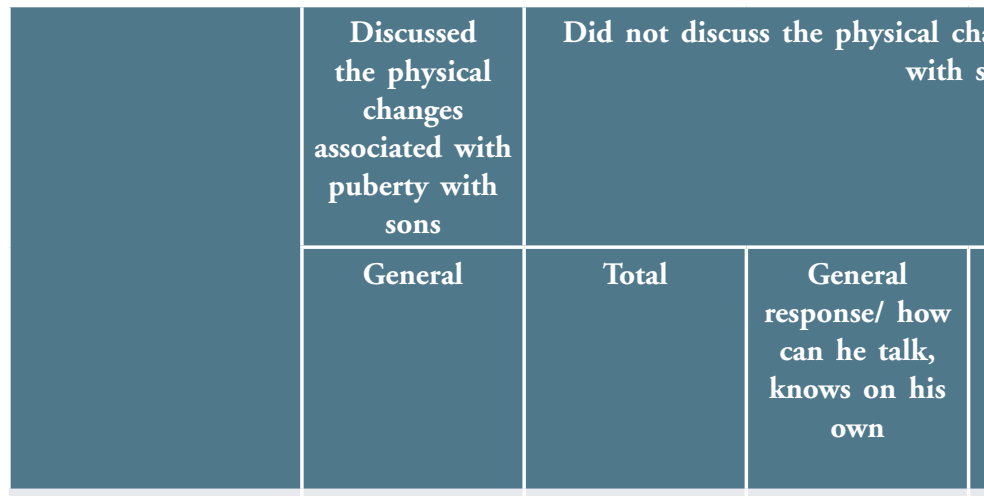

No, not
even with
respondent's
spouse; may
have talked to
someone else

Not with

respondent;

maybe with

respondent's

spouse

\section{A. MOTHERS}

Bihar

Jharkhand

Rajasthan

Maharashtra

Andhra Pradesh

Tamil Nadu

\section{Total}

Urban

Rural

\section{B. FATHERS}

Bihar

Jharkhand

Rajasthan

Maharashtra

Andhra Pradesh

Tamil Nadu

Total

Urban

Rural
18

21

16

12

15

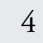

86

30

56

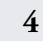

4

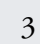

\section{5}

2

1

1

-

12

\section{5}

7

12

11

8

16

12

10

69

24

45
13

14

9

9

13

4

62

20

42
Total whose narratives addressed

whether they had discussed

the physical

changes

associated with

puberty with

their sons
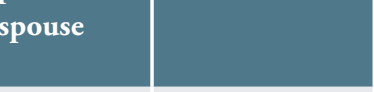
Yes, he asked me why his voice was getting heavy. I told him not to worry as things would get normal pretty soon. [Mother, Bihar, rural, aged 55 years, Class 10]

Yes. We talk about the physical changes occurring in the body as one grows up. When he has some (such) problem, he tells me that he has a particular problem or that such and such things are happening to him. [Mother, Bihar, rural, aged 36 years, no education]

If his beard grows, I tell him to shave. I have told him to shave and get the barber to shave him. [Father, Andhra Pradesh, rural, aged 44 years, no education]

He does ask about his beard and moustachewhether he should shave. Then I tell him not to let it grow; it is better to shave. [Father, Bihar, urban, aged 46 years, Class 12]

Several parents reiterated, however, that discussion did not take place. For example:

I: Did Mahesh ask anything about the changes happening in his body during puberty?

R: No, how could he ask?

I: Did he ask your husband (his father)?

R: No. [Mother, Jharkhand, rural, aged 40 years, no education]

We did not explain to him.... His father talks to him sometimes but he doesn't talk about such things. [Mother, Rajasthan, rural, aged 45 years, no education]

No, such conversations (about physical changes associated with puberty among boys) don't happen among us. No. He doesn't talk about all these things with his father either. [Mother, Bihar, urban, aged 44 years, no education]
I: Did you tell them about the changes in the body that come about while growing?

R: No, I did not talk about those. Those are natural.

I: Your son?

R: No.

I: Did your son talk with his father about those?

R: No. [Mother, Andhra Pradesh, urban, aged 48 years, Class 10]

I: Have you ever discussed with your children?

R: Till now I have not talked to them as such about physical changes and puberty. [Mother, Tamil Nadu, urban, aged 54 years, Class 10 and teacher training]

I have never discussed such things with them... [Father, Maharashtra, rural, aged 50 years, graduate]

(I) did not tell my son (about the changes that occur during puberty). (I) did not tell him as he never experienced any problems. [Father, Andhra Pradesh, rural, aged 48 years, Class 6]

No. We don't tell (children) such things (physical changes). [Father, Andhra Pradesh, urban, aged 52 years, no education]

I have never talked, and he also has not asked about his growth (valarchi) and about (sexual) relationships (uravumurai), [Father, Tamil Nadu, urban, aged 41 years, Class 10]

\section{Communication about matters relating to sex, pregnancy and/or sexually transmitted infections/HIV}

A great majority of parents who were interviewed in-depth reported that matters relating to sex, 
pregnancy and/or sexually transmitted infections/ HIV were rarely discussed with their children (Table 3.3). Indeed, just 12 and 13, respectively, of the 164 mothers $(7 \%)$ and 137 fathers (10\%) who discussed this topic in the course of the interview reported that they had talked to their children about such matters (Panels A and B, respectively). Young people's own reports suggest a roughly similar situation: fewer than 1 percent of young men and 0-6 percent of young women reported having discussed reproductive processes with a parent (IIPS and Population Council, 2010).

Table 3.3 further shows that urban-rural differences in parents' responses were narrow: six each of the 61 urban and 103 rural mothers $(10 \%$ and $6 \%$, respectively) (Panel A) and 4 of the 51 urban fathers and 9 of the 86 rural fathers $(8 \%$ and $10 \%$, respectively) (Panel B) had communicated with their children on these issues. Among the few who had discussed matters relating to sex, pregnancy and/ or sexually transmitted infections/HIV with their children, communication was typically gendered, with fathers communicating with sons and mothers with daughters.

Even those parents who reported talking to their children about such sexual matters had typically spoken in generalities—warnings about "staying away" from the opposite sex, not engaging in "bad" behaviour, not watching films with sex scenes and so on. Occasionally, parents appeared to have conveyed information that was inaccurate.

Narratives of mothers from all six states who reported communicating with their children about sex suggest that communication was very general, need-based, and focused on appropriate behaviour and not necessarily on sexual and reproductive health matters. For example:

Yes. We have to tell our children. I give him examples of someone we have watched on $T V$.
That's why we must caution our children. From the time Jitendra was 16 years old, I have been telling him.... I told him after watching TV you must not behave like that (close interaction with girls); if you behave like that then such things (infection, loss of reputation) can happen.... I tell him every day to be good and not get involved in anything that is wrong. I tell him not to get involved in drinks (alcohol); that we must not spoil our name and should progress and move forward in life. [Mother, Maharashtra, rural, aged 49 years, Class 2]

I told my daughter before her marriage (about marital relations). I told her she should not be afraid and should not shout loudly. [Mother, Andhra Pradesh, rural, aged 46 years, Class5]

Yes, I told her what marriage means. In our religion, it is like this: when a girl gets married, we explain to her about our system: how to behave with the in-laws, and if the in-laws say anything not to answer back. [Mother, Maharashtra, urban, aged 55 years, no education]

Fathers from all six states who reported communicating with their children (almost entirely their sons) on sexual relations reported warning them about "bad" behaviour, for example:

I have always taught (him) to stay within limits, never walk on the wrong path. The world will laugh at you (I said), so never get involved in wrong things. This knowledge I have provided him. [Father, Jharkhand, rural, aged 49 years, Class 2]

I have told him that he needs to go up in life; therefore, he needs to concentrate on his career rather than girls, [Father, Rajasthan, rural, aged 39 years, Class 7] 
I have warned him. I have asked him not to go around with friends, not to go to the cinema, and not to watch sex movies. He has not watched such movies but when he mingles with friends he may feel inclined to do so. So, I have warned him not to do so. [Father, Tamil Nadu, rural, aged 48 years, Class 5]

(If) we explain a little, then they might understand. I give him an example (of an incident) that happened in the neighbourhood. A boy who had studied MA got addicted to drinks; he had no job and due to bad company he got spoilt. I give him such examples and warn him. I tell him that a husband and wife relationship is good only after marriage. [Father, Tamil Nadu, rural, aged 50 years, Class 10]

I told him... he may require many years to get a good name but he will get a bad name within a minute. So, we should follow some restrictions. We should not have any (bad) habits... like drinking, gutka (containing betel nut, tobacco etc), cigarettes and girls. [Father, Andhra Pradesh, urban, aged 54 years, Class 9]

A few fathers and mothers reported informing their children (by and large, gendered as above) about HIV and its life-threatening consequences. For example, one father reported:

I have told him about the diseases that can occur due to bad relations. I have told him not to talk to girls. [Father, Andhra Pradesh, urban, aged 52 years, no education]

And in just one narrative, a father described discussing sex with his daughter:

She is absolutely frank. Not just with her mother; she talks to me about everything (sexuality-related issues) in the medical field, and I tell her not only as a father but also as a teacher. [Father, Bihar, urban, aged 45 years, graduate]
More mothers described their discussions; as the quotes below suggest; three of these mothers were unique in some way. For example, one worked as a counsellor, the daughter of a second was receiving higher education and was well-informed about these matters, and a third was visited by a nurse who conveyed information to the mother who then passed it on to her daughter:

I: Have you discussed with him about sexual relationships between boys and girls?

R: I have told him about it. The environment in the village and the school is like that. There are both boys and girls in school and they participate together. They sit together. During that time, they exchange ideas. They discuss the effects of certain behaviours; (to) be careful about certain diseases... I am involved in social service; I am responsible for health matters... I explain to them about the dangers involved, and how lives of boys and girls are destroyed if they misbehave. [Mother, Maharashtra, rural, aged 43 years, Class 12]

Yes, she talks about it. About the diseases and infections and the way in which they happen.... Yes, I did feel shy. But what to do? I have to teach her these things. [Mother, Bihar, rural, aged 30 years, educated in Madarasa]

Yes. I did talk to him once. Meaning, he goes outside the village with the boys; so I told him that because he goes with boys, it shouldn't happen that he gets involved with someone-with some girl or woman. I said, 'You know what happens if you do this. You can get a disease. So you should not do all this.' [Mother, Jharkhand, urban, aged 42 years, Class 7]

A nurse comes here; she told me (about AIDS)

and I explained it to Manju. [Mother,

Rajasthan, urban, aged 42 years, no education] 
Table 3.3

Extent of communication between parents and daughters/sons about sexual and reproductive health matters
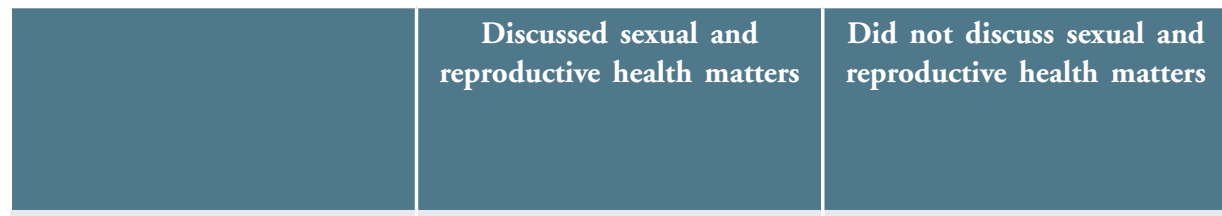

Total whose narratives addressed whether they

had discussed sexual and

reproductive health issues

\section{A. MOTHERS}

Bihar

Jharkhand

Rajasthan

Maharashtra

Andhra Pradesh

Tamil Nadu

1

2

4

3

2

-

Total

Urban

Rural

\section{B. FATHERS}

Bihar

Jharkhand

Rajasthan

Maharashtra

Andhra Pradesh

Tamil Nadu

Total

Urban

Rural
12

6

6

2

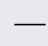

4

$-$

4

3

13

4

9

with their daughters/sons

Yes. I explained to her about the diseases of the private parts (gupt yaun roag, andar ki bimari).

[Mother, Rajasthan, urban, aged 45 years,

Class 5]

That the information conveyed may not always have been accurate is evident from the following quotes from a father and a mother:

Yes. I had explained to her that she should clean her private parts well after toilet, and should drink only one cup of tea as drinking more tea leads to white discharge and frequent periods because it increases the heat in one's body. [Mother, Rajasthan, urban, aged 45 years, Class 5]
I have told my son that if there is a problem in passing urine, circumcision must be done. I have told my daughter that if there is a problem with menstruation, she should take a tablet or see a lady doctor. Also, take nutritious food. Whether she asks or not, I tell her that food should be taken at the proper time. [Father, Tamil Nadu, urban, aged 55 years, graduate]

Table 3.3 also indicates that the large majority of parents acknowledged that they had not spoken to their children about sex, pregnancy or sexually transmitted infections/HIV: 152 of the 164 mothers (93\%) and 124 of the 137 fathers (91\%) Urbanrural differences were, once again, negligible: 55 of 
the 61 urban mothers $(90 \%)$ compared to 97 of the 103 rural mothers $(94 \%)$ had not discussed these matters with their children (Panel A); likewise, 47 of the 51 urban fathers $(92 \%)$ and 77 of the 86 rural fathers $(90 \%)$ so reported (Panel B).

Narratives from mothers suggest the following: I have never done such a thing (talk about sex).... Everything need not be talked about. [Mother, Bihar, rural, aged 45 years, no education]

I never told her anything about girls' growth or topics about sex. [Mother, Jharkhand, rural, aged 40 years, no education]

We did not explain anything to Asuram. His father talks to him sometimes but he doesn't talk about such things. [Mother, Rajasthan, rural, aged 45 years, no education]

No. How can we tell? I didn't tell her. How can we tell our own daughter? I didn't tell her since I am her mother. [Mother, Andhra Pradesh, rural, aged 43 years, Class 9]

No. I did not tell him. Elders tell them that both have to sleep in one bed. [Mother, Andhra Pradesh, rural, aged 50 years, no education]

I: Has your son ever talked with you about sexual relationships?

R: How can he talk about this with his mother?

I: With his father?

R: He has not talked about it. [Mother, Tamil Nadu, rural, aged 48 years, Class 6]

Does anyone talk about this with his mother (thai) who has delivered him? He doesn't talk about these things. [Mother, Tamil Nadu, rural, aged 55 years, Class 5]
I: Have you ever discussed the relationship of a man and a woman after marriage?

R: No, never. Why would I ask my son about these things? [Mother, Bihar, urban, aged 40 years, no education]

I: Have you talked with Anju (daughter) about the relations of married life (husband-wife relations)?

R: $\quad N o$.

I: Have you discussed this matter with Lalu?

R: No. I have not talked about all that. [Mother, Jharkhand, urban, aged 40 years, no education]

We don't suffer from any such diseases and have never talked about them. [Mother, Rajasthan, urban, aged 40 years, Class 8]

No. How could I tell these things to my daughter? [Mother, Maharashtra, urban, aged 35 years, Class 9]

No, I have never spoken to them about these things. We (mother and father) have never slept together in front of children. My daughter and I sleep on the floor and Shiraj and his father sleep on the bed. It all depends on how we behave in front of them. If there is any bad scene on $T V$, they change the channel. [Mother, Tamil Nadu, urban, aged 35 years, Class 5]

The same general perceptions were articulated by fathers:

He talks to me on almost all issues. Almost all types of talk except that related to physical relationships and reproduction. [Father, Rajasthan, rural, aged 39 years, Class 7] 
It is not possible to speak with parents like that (on topics of sex and reproduction).... It is wrong for parents to give such information (to their children). [Father, Maharashtra, rural, aged 40 years, Educational attainment level not available]

He has not asked me (about sexual relationship) and, I have not talked to him about it either.

[Father, Tamil Nadu, rural, aged 48 years, Class 5]

No, I have never given sex-related information or how one gets infected with AIDS or other sexual diseases to my sons. [Father, Jharkhand, urban, aged 43 years, Class 3]

No, he hasn't asked me (about sexual matters). We haven't told him. We don't talk about these things to our children. [Father, Andhra Pradesh, urban, aged 52 years, no education]

\section{Summary}

Interaction between parents and their adolescent children about sexual and reproductive health matters was limited in all six states, irrespective of the sex of the parent or urban-rural residence. This was so even in the southern states which showed closer parent-child relationships, particularly between mothers and daughters, and a less authoritarian style of communication.

Discussion on the physical changes associated with puberty was, however, gendered, both in terms of communication with daughters versus sons, as well as in terms of communication by the mother versus the father. For example, communication focused far more on the girl than the boy. For girls, it focused on the mechanics of menstruation- "use of the cloth" and dos and don'ts of appropriate behaviour during menstruation, and as a result of her new status as a mature person rather than on the meaning of menstruation and the menstrual cycle and its links with pregnancy. Even so, many mothers specifically noted that girls were not provided with information about menstruation until it happened, and as a result, many described their daughters' fears and bewilderment about it when it occurred. Moreover, many others reported discomfort stemming from shyness and shame/embarrassment about discussing even menstruation with their daughters, many leaving it to other women in the family, most often grandmothers and aunts, to convey information to children. Communication with sons, in contrast, was typically absent, with a few parents mentioning the growth of facial hair and voice change. Gender differences were also evident in terms of communication by the mother as opposed to the father. Fathers were somewhat more likely than mothers to have communicated with their sons about the physical changes associated with puberty, but the extent of their communication was typically limited. In contrast, fathers almost never communicated with their daughters on this issue, commenting rather that this type of information could only be conveyed by the mother or other female relatives.

While communication on the physical changes associated with puberty was clearly gendered, this was not so evident in parents' narratives about communication on sexual and reproductive health matters relating to sex, pregnancy and/ or infection. Notwithstanding the fact that both mothers and fathers were typically reticent about providing their children with such information, findings point to a change among some parents towards a greater willingness to discuss sexual and reproductive health matters with their children, a change perhaps resulting from their concerns about the consequences of HIV/AIDS. For example, in 
contrast to conventional indirect messages exhorting children to be good, not to get involved in wrong things, not to spoil the family's reputation and so on, the narratives of these parents indicate that they cautioned their children more directly, reporting messages designed to instil fear, most often about the links of 'bad' behaviour with HIV and its lifethreatening consequences. Additionally, a few parents who reported communicating with their children on these matters were themselves misinformed and conveyed misconceptions to their children.
As noted in Chapter 1, we acknowledge that it was difficult to elicit in-depth responses from parents on communication on sensitive matters in all situations, and that responses were not equally expansive in all settings. As this chapter has shown, the discussion and the depth of narratives differed, with responses in some settings richer than those in others, and with narratives relating to parent-child communication on the physical changes associated with puberty more expansive than those relating to sex, pregnancy or sexually transmitted infections/ HIV. 


\section{CHAPTER 4}

\section{Obstacles to communication about sexual and reproductive health matters}

Parents were probed about their experiences and perceptions about the reasons for their limited discussion on the physical changes associated with puberty and/or such sexual and reproductive health matters as sex, pregnancy and infection. A total of 145 mothers (98 and 47 from rural and urban areas, respectively) and 97 fathers (54 and 43 from rural and urban areas, respectively) elaborated on the reasons for their limited communication with their children on these matters, and/or their preferences about whether their children should obtain this information.

As suggested in Table 4.1, reasons for not communicating with children on sexual and reproductive health matters fell into four major groups: that such discussion went against cultural norms, including that discussion on such matters was unacceptable: that children, and girls in particular, should not know about sexual matters until marriage or that they should not be informed about these matters till much older; that parents were uncomfortable due to shame, or shyness about holding such discussions with their children and alternatively, for much the same reasons, children were uncomfortable about doing so with a parent; that young people today became aware of these issues on their own; and finally, that explaining these matters to children would lead them to engage in sexual activity. While not an obstacle, several parents cited young people's preference to obtain this information from extended family members as a reason for not communicating with their children about sexual and reproductive health matters. This chapter discusses all of these obstacles.

\section{Cultural norms and unacceptability of discussion on sexual and reproductive health matters}

A large group of parents- 80 mothers and 55 fathers $(55 \%$ of the 145 mothers and $57 \%$ of the 97 fathers) — who had elaborated on their reasons for not communicating with their children about sexual and reproductive health matters, reported that it was not culturally appropriate for them to provide their children with information about such matters (Table 4.1). Interestingly, while about as many (55\%) rural as urban mothers reported this perception (54 of the 98 rural mothers compared to 26 of the 47 urban mothers) (Panel A), fewer rural than urban fathers so reported: 28 of the 54 rural fathers $(52 \%)$ compared to 27 the 43 urban fathers (63\%) (Panel B).

Several of these parents noted that discussion about sexual relations was unacceptable socially and culturally and hence, not done in their settings. For these parents, sexual matters were clearly a matter of shame, and were not something to be discussed within parent-child relationships. For example, narratives from rural and urban mothers highlight the following:

No, all these things (discussing about physical relationship with children) don't work in our village. No, all this does not work in our society.

[Mother, Jharkhand, rural, aged 39 years, no education] 
No. How can I tell her such things? Parents cannot tell daughters about such sensitive matters. This is told to them by their girl friends. Parents feel shy to talk about such things. After all, I am her mother; she cannot talk (to me) about it. [Mother, Maharashtra, rural, aged 42 years, no education]

It's wrong. Parents should not tell (their children about sexual matters). [Mother, Andhra Pradesh, rural, aged 50 years, Class 10]

This is a matter of shame. Why should I share it with the children? [Mother, Jharkhand, rural, aged 45 years, no education]

Narratives from fathers about discussing sexrelated matters with their children were less expansive, but suggest a similar perception:

I will not be able to tell them (sons) because of our relationship of father and son. I will not be able to tell them. I will be able to tell a third party, or I will be able to tell anyone else. [Father, Maharashtra, rural, aged 52 years, graduate]

To talk (pause) with your sons and daughters is not possible. Parents will not talk like that because our culture is not that type. [Father, Maharashtra, rural, aged 55 years, graduate]

In the community, you will never find any mother or father who speaks to their children on this topic. [Father, Rajasthan, urban, aged 42 years, Educational attainment level not available]

Parents' narratives further suggest that marriage is a marker legitimising the provision of information on sexual relations to children. For example, 18 mothers (and two fathers) clearly indicated that children should not be given such information until after marriage, and some others noted that once married, their children would come to know about these matters on their own. For example:

No. One should not tell them about these things (sexual relations). When they get married, they will themselves come to know about these things. No. One should not tell boys either before they get married. [Mother, Bihar, rural, aged 45 years, no education]

No. One should not tell their children about all these things; (one should) let them learn about these things after they get married. We should not say anything about sexual relationships to our children before they get married. [Mother, Jharkhand, urban, aged 42 years, no education]

A girl must not be given this information before marriage; (she will) automatically come to know after marriage. [Mother, Maharashtra, rural, aged 40 years, Class 5]

I will tell her at the time of her marriage but not before. We cannot tell her before that because of shyness. [Mother, Andhra Pradesh, rural, aged 35 years, no education]

Despite the fact that all parents were referring to children aged 15 or older, several suggested that in their setting, discussing sexual matters was only acceptable at an older age. For example:

How do we discuss such private issues? He is only a 15-16 year-old boy. As of now, what can I tell him? [Mother, Bihar, rural, aged 35 years, no education]

He is not big (old enough to discuss sexual matters. Soon he will get married. [Mother, Rajasthan, rural, aged 48 years, Educational attainment level not available] 
She is a small girl and she need not know about these things (sexual relations). [Mother, Tamil Nadu, urban, aged 35 years, Class 5]

What would I say to a young girl (about sex)? [Mother, Jharkhand, rural, aged 38 years, Class 5]

\section{Discomfort in discussing sexual and} reproductive health matters: Lack of awareness and embarrassment

Closely related with cultural norms that dissuaded parents from speaking to their children on sexual and reproductive health matters was the discomfort they experienced, either because they lacked awareness themselves, or, more frequently, because they were shy or embarrassed to communicate on such matters with their children. A large group of 50 of the 145 mothers (34\%), and a smaller group of 22 of the 97 fathers (23\%) so reported (Table 4.1, Panels A and B, respectively). Moreover, more rural than urban parents so reported: for example, 36 of the 98 rural mothers $(37 \%)$ compared to 14 of the 47 urban mothers (30\%) reported shyness (Panel A), as did 17 of the 54 rural fathers $(31 \%)$ and five of the 43 urban fathers (12\%) (Panel B).

For some, discomfort arose from their own lack of awareness about sexual and reproductive health matters, as these narratives suggest:

This education has to be given. How to go about it? What can I tell him when I myself am not able to understand? [Father, Jharkhand, rural, aged 48 years, Class 3]

What will the parents tell them? They have no education at all. In villages, we don't get such education. [Father, Rajasthan, rural, aged 47 years, Class 8]
If he asks me, I don't have much knowledge about that (sexual matters) to explain to him. [Mother, Maharashtra, urban, aged 31 years, postgraduate]

I don't know enough to be able to answer any question. [Mother, Maharashtra, rural, aged 35 years, Educational attainment level not available]

For many parents—rural mothers in particularthere was, however, a sense of embarrassment or awkwardness about discussing sexual and reproductive health matters with both sons and daughters, clearly related to the cultural norms prohibiting discussion between parents and children about the physical changes associated with puberty and/or sex and reproduction. With regard to shyness in discussing these matters with their daughters, mothers expressed the following:

I would not ask her anything about it (menstruation). I would feel bad (to ask). ... Yes, I would feel very shy. When one's daughter grows up, one is bound to feel shy. [Mother, Bihar, rural, aged 45 years, no education]

I feel shy. How will I not feel shy? [Mother, Jharkhand, rural, aged 38 years, Class 5]

How can parents give this information (sexual and reproductive matters). All of them feel shy about it. [Mother, Maharashtra, rural, aged 39 years, Class 9]

I did not tell them such things (about sex and reproduction). How can we tell them all these things? I don't know. I was shy. [Mother, Andhra Pradesh, rural, aged 49 years, no education] I feel a little awkward about talking about it (sexual matters). Yes, I was feeling shy to discuss it with Shivani. [Mother, Bihar, urban, aged 32 years, postgraduate] 
We cannot tell her about such relations. I feel shy to tell her. [Mother, Maharashtra, urban, aged 35 years, Class 4]

Mothers were even shyer about discussing sexual matters with their son:

No. How can he talk to me on this topic? No, how could he ask me? [Mother, Jharkhand, rural, aged 54 years, Educational attainment level not available]

No. He is a boy and I am his mother; so I can't talk to him regarding all this. [Mother, Rajasthan, urban, aged 40 years, Class 8] Once he saw a 'Carefree' (sanitary napkins) advertisement on TV and asked me what it is. He was studying in the 8th standard (then). I did not know what to answer; I asked him to go away. [Mother, Tamil Nadu, rural, aged 40 years, Class 12]

No, I will not be able to tell him (about sexual matters). I will feel shy to tell him. [Mother, Maharashtra, urban, aged 31 years, postgraduate]

In our community, you will never find the mother and father speaking to their children on this topic. [Mother, Rajasthan, urban, aged 31 years, postgraduate]

While few fathers who expressed shyness expanded on their perceptions, one father lamented his shyness as follows:

(It is) good to tell them (about sexual matters). But we feel shy. Both the listener and the one who tells feel shy. [Father, Andhra Pradesh, rural, aged 60 years, no education]

Some parents whose narratives elaborated on the nature of discussion-considerably more mothers
( 42 of 145 or $29 \%$ ) than fathers (8 of 97 or $8 \%$-reported that communication was limited because their son or daughter was too shy to engage in a conversation with them about sexual and reproductive health matters (Table 4.1, Panels A and $B$, respectively). Now, a larger proportion of urban than rural parents so reported: 18 of the $47(38 \%)$ compared to 24 of the 98 (24\%) urban and rural mothers, respectively (Panel A), and five and three of the 43 and 54 urban and rural fathers $(12 \%$ and $6 \%$ ), respectively (Panel B).

For example, mothers reported the following with regard to their daughter:

I wanted to ask. One day I even sat (with my daughter) to ask about it, but she got up and ran away. I have tried to ask her, but she doesn't tell me. [Mother, Jharkhand, rural, aged 36 years, no education]

Before she got married, she used to feel shy to talk about these things (husband-wife relationship). After she got married, she talks to me about everything. [Mother, Jharkhand, urban, aged 48 years, Class 9]

No. children as well as parents feel shy to talk about these things. [Mother, Rajasthan, urban, aged 49 years, no education]

But when I try to tell her, she tells me to keep quiet; that she knows everything. Girls feel shy to share with their parents; they can speak freely with their friends but they feel shy to speak to their mother. [Mother, Maharashtra, urban, aged 38 years, Educational attainment level not available]

With regard to their son, mothers reported thus with regard to sexual and reproductive health matters 
Whenever he asks questions, we are able to reply to him properly. He doesn't talk much because he is the eldest son and feels very shy towards us. But sometimes he talks to us.... She (daughter) too doesn't speak much. She also feels shy. They are all kids. [Mother, Jharkhand, rural, aged 35 years, Class 2]

He does not talk as he feels shy. Even with his father, he feels shy. No, he should not talk about these things. We all feel shy, be it him or us. [Mother, Rajasthan, rural, aged 48 years, Educational attainment level not available]

The few fathers who perceived that their children were too shy to communicate on sexual and reproductive health matters reported as follows:

Girls feel shy to talk about such things with their father. [Father, Rajasthan, urban, aged 37 years, Class 12]

But children will not ask at all. They (boys) don't have that much daring. They will ask their friends. Or they may ask a third person. Suppose I have just become an adult (attained puberty), how can I talk to my parents? How can I ask them to get me married? But I can speak about it to my friends, or to a third party. I can also speak to a friend of my father. But I cannot speak directly to my parents. [Father, Maharashtra, rural, aged 55 years, graduate]

These questions should be asked but in a highsociety family. In such families, they (parents and children) don't feel shy. In our middle class families, children will not ask their parents as they feel bad to ask them. Our children will not ask us and we will not tell them. [Father, Maharashtra, rural, aged 55 years, Educational attainment level not available]
He may be thinking how he can approach his parents about these things (sexual matters).

[Father, Rajasthan, urban, aged 37 years, Class 8]

Several parents who reported that they or their children were too shy to discuss these matters appeared to rely on extended kin to assume the role of informing their children about sexual and reproductive health matters. In general, these parents suggested that their children were more comfortable communicating on these matters with extended family kin, and that they themselves could not approach their children on these matters. Several women (and not a single father) reported that their daughter-and in a few cases their son-discussed these issues with a relative rather than their own mother. For example:

She did not share it with me but she shared this matter with her aunt (chachi). [Mother, Jharkhand, rural, aged 45 years, no education] He has an elder brother (cousin) with whom he discusses these matters. [Mother, Jharkhand, rural, aged 34 years, Class 6]

All this can be told by the grandmother. Her grandmother and girl friends should advise her properly. It is for this reason that you should have friendship with good girls. They should ask such friends only. Or, her grandmother should ask her about it; her grandmother can speak about it (smiles again). How can I ask my daughter about it? [Mother, Maharashtra, rural, aged 42, no education]

No. Girls feel shy to talk to their mother about such things; they talk to their aunt who is of their age and discuss what is to be done. [Mother, Rajasthan, urban, aged 40 years, Class 8] 
While not an obstacle as such, young people's preference for obtaining this information from extended family members rather than their own parents was clearly a factor underlying parents' limited communication with their daughters and sons on sexual and reproductive health matters.

\section{Children come to know about sexual and reproductive health matters on their own}

A large group of parents argued that young people came to know of sex and reproduction on their own: through friends, through the mass media notably TV, and simply because they are more educated than earlier generations, and hence parents need not provide this information (Table 4.1). This perception was articulated by 95 of the 145 mothers (66\%) and 56 of the 97 fathers (58\%) from the six states. Urban-rural differences were generally narrow: 32 of the 47 urban (68\%) and 63 of the 98 rural (64\%) mothers; 23 of the 43 urban (53\%) and 33 of the 54 rural $(61 \%)$ fathers (Panels A and B, respectively).

Table 4.1 also suggests that about half of both mothers and fathers who reported that they had not spoken to their children about these sensitive matters perceived that their sons and/or daughters had been informed about sex and reproduction by their friends, their siblings, siblings-in-law and so on: reported by 70 of the 145 mothers (48\%) and 47 of the 97 fathers (48\%). Urban-rural differences were not observed. For example:

I: So, with whom does she talk to about all this?

R: She will talk to her brother's wife or her friends. [Mother, Jharkhand, rural, aged 39 years, no education]

She gets to know about such things from her friends and through the TV. [Mother, Bihar, urban, aged 45 years, no education]
These days boys and girls come to know everything by themselves, they talk amongst themselves. [Father, Rajasthan, rural, aged 43 years, no education]

About sexual topics, they do not speak to anybody; not even their father. They have got a few friends from whom they come to know. Not from the parents; in rural areas, it (speaking to parents about such matters) doesn't happen. [Father, Maharashtra, rural, aged 40 years, no education]

We haven't talked about anything related to this (sexual matters). They are boys and are growing up; they must be talking about this with their friends. Nowadays, almost all the boys living in the city are aware of AIDS. [Father, Bihar, urban, aged 46 years, Class 10]

Table 4.1 further shows that several fathers and a few mothers spoke generally about how today's youth understand sexual and reproductive health matters from their environment more generally by observing what is happening around them:

What does one have to tell children of today's generation? They know everything, I feel. They have developed maturity; so I hope they know everything. [Mother, Jharkhand, urban, aged 40 years, Class 10]

Nowadays there is no need to tell the children; they understand everything. When we see animals having sex; then, we understand ourselves. That's why I feel there is no need to tell the children. Boys and girls come to know through their friends, or by watching television or animals and birds. There is no need for parents to tell them. [Father, Maharashtra, urban, aged 43 years, Educational attainment level not available] 
Nowadays, all (children) are very smart. There is no need to talk to them about these matters. You are asking olden days' questions. [Father, Andhra Pradesh, urban, aged 49 years, Class 7]

There is no need to tell our children. Children are observing what is happening. They are learning from others about how to behave. So, there is no need to tell them anything. There is no need to tell children of the present generation.

[Father, Andhra Pradesh, urban, aged 38 years, Class 8]

Young men may be discussing (sex and reproduction). Nobody tells this to anybody. It becomes known casually. [Father, Andhra Pradesh, urban, aged 60 years, no education]

A relatively smaller number of parents (25 of the 145 mothers and nine of the 97 fathers, or $17 \%$ and $9 \%$, respectively) also suggested that their children may have learned about sexual and reproductive health matters from the TV, books and newspapers (Table 4.1, Panels A and B, respectively). Again, rural-urban differences were narrow, although urban mothers were more likely than rural mothers, and urban fathers somewhat less likely than their rural counterparts, to so report. For example:

Children these days get to know so much from $T V$ and school. There is no need to tell them anything. [Father, Bihar, urban, aged 44 years, Class 10]

Now, what will I tell her beforehand? Nowadays, educated children get to know all this beforehand. Earlier, because children were uneducated, they had to be told all this; but girls today read all this in books and come to know about it. [Mother, Jharkhand, rural, aged 36 years, no education]
Nowadays, with increasing age they watch everything on TV. Therefore, it is not necessary to tell them about it. Earlier, as children were married at a very young age, and there was no $T V$, they were not aware (of sexual matters). Now, they get married much later. Therefore, it is not so necessary to tell them about it. [Mother, Maharashtra, rural, aged 50 years, Class 11] When they were becoming adult, my daughters never asked me anything. My son too did not ask me. They know everything. They know about it; then why should I tell them? They come to know everything from the TV and movies. [Mother, Maharashtra, rural, aged 55 years, no education]

They come to know by watching TV. Many scenes are shown on TV. [Mother, Andhra Pradesh, urban, aged 48 years, Class 10]

They know everything as they watch $T V$ and cinema. In the past, parents used to tell (their children) how a wife and husband should be (busband-wife relationship). There is no need to tell present-day children. They know everything. [Mother, Andhra Pradesh, rural, aged 45 years, no education]

They know all about that (how to behave with their husband). Nowadays, even uneducated girls know this due to the TV and books. They know very well. They also come to know through their married friends. [Mother, Andhra Pradesh, urban, aged 46 years, Class 10]

Several parents who argued that young people came to know of sexual and reproductive health matters on their own acknowledged a generational difference. They alluded to the fact that their children were well-educated and widely exposed to the mass media and, by virtue of this better 


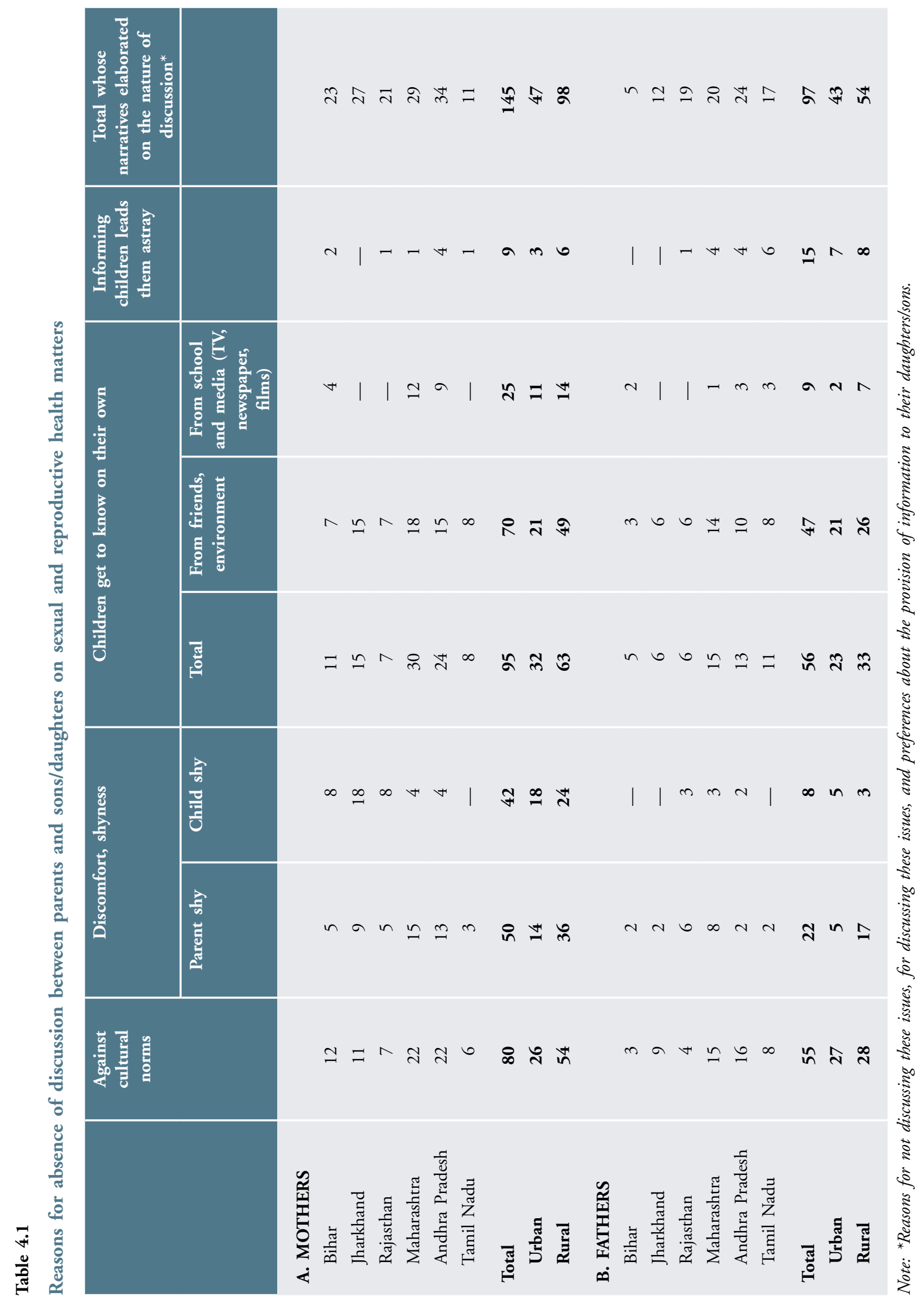


education and greater mass media exposure, were better aware than their parents about sexual and reproductive health matters. For example:

Nowadays, educated children get to know all this (sex and reproduction) beforehand, [Mother, Jharkhand, rural, aged 36 years, no education]

I have not said anything about those (sexual and reproductive) matters. They (children) know everything as they are educated. We should tell these things to people who don't know. There is no need to tell those who already know.

[Mother, Andhra Pradesh, rural, aged 39 years, Class 4]

They know everything. We may not know about it (sexual and reproductive matters) but children know about everything. Still, we ask them to behave in a certain manner. [Mother, Tamil Nadu, rural, aged 45 years, Class 6]

No, I didn't say anything to him. Nowadays, children are smart because they watch $T V$, and know all this before marriage. As the new generation is educated, they must explain to us - the world has changed. The children are smart and they don't get scared to do anything wrong. [Mother, Maharashtra, urban, aged 55 years, Educational attainment level not available]

She is an intelligent girl and has knowledge about all these things; (in fact) it (knowledge) is a little more than normal or required. What can she ask her mother? She had studied about all these things in 12th class, and so she has increased her knowledge about these things. So what could she ask her mother? She knew it very well. [Father, Bihar, urban, aged 45 years, graduate]

\section{Fears that children will go astray if given information about sexual and reproductive health matters}

A few parents expressed concern that communicating with children on sexual and reproductive health matters would encourage young people to engage in sex or perceive the communication as parental approval of such activity (Table 4.1). While not expressed, it is possible that many of those who reported that communicating with children on sexual and reproductive health matters was culturally unacceptable, or was unnecessary were also expressing this concern indirectly. A total of nine of the 145 mothers $(6 \%)$ and 15 of the 97 fathers (15\%) (Table 4.1, Panels A and B, respectively) articulated this view. Mothers responded thus:

No. [Parents] should not tell children. Otherwise they will get spoilt. [Mother, Andhra Pradesh, rural, aged 35 years, Class 7]

No. No. I have not told them those matters, as I am their mother. I have told them about all other things... Not necessary. It is like parents teaching that. [Mother, Andhra Pradesh, rural, aged 45 years, no education]

She will become spoilt if I tell her such matters.

[Mother, Andhra Pradesh, rural, aged 32 years, Class 7]

No. They will become spoilt. They will go in the "galat" (wrong) line (path). [Mother, Bihar, urban, aged 45 years, no education]

If we give such information to Amit, he will feel that his mother is telling him such-andsuch a thing; I think that is not good. [Mother, Maharashtra, urban, aged 38 years, Educational attainment level not available] 
Among fathers, four to six fathers from

Maharashtra and the southern states, compared to hardly any in the northern states, so expressed: Sometimes, I bring home books about sexual relationship but I do not think it is proper to let children see such books. Such books should not be given to children as reading these books could have some (adverse) effect on them. So I dare not give the books to my children. There is a book called "Celibacy (bramhacharya) is life". I felt like giving that book to them. They will pick up good things from it at least, and not the bad things. [Father, Maharashtra, rural, aged 60 years, graduate and B.Ed.]

If at all our daughter asks us such questions (about sexual and reproductive matters), our first duty would be to look at her and read her face, and try to analyse why she is asking such questions. [Father, Maharashtra, rural, aged 46 years, Educational attainment level not available]

In a village, parents will never tell their children about such matters. Every parent thinks that such things should not be told to children. They don't realise that it is good if known to children. They fear that their children will engage in such activities if they know. When children make mistakes, they (parents) shout at them... as a result, they (children) feel scared to ask their parents about anything; hence, such a situation (of speaking about sex-related matters) doesn't arise. They [parents] understand it wrongly like this. [Father, Andhra Pradesh, rural, aged 55 years, Class 1]

Yes. If the one who doesn't have any knowledge is taught about this he would start doing mischief (chettai). This education would give youngsters the opportunity to become bad (kettu poka). [Father, Tamil Nadu, rural, aged 48 years, Class 10]

Earlier, such education was not given to boys and girls. Now, the government has approved such education. But I think the government should not agree to it. It has a bad effect. There are men and lady teachers, and both boys and girls come to the class. Its effect can be both good and bad. [Father, Maharashtra, urban, aged 43 years, Class n.a.]

He will be curious to know what will happen next. The chances of going on the wrong path are greater. Therefore, we don't discuss such topics. [Father, Maharashtra, urban, aged 44 years, Class 7]

No. It is wrong. If we discuss about that, they may think about that. If we tell him not to go in a particular way, he will think about it and go that way. [Father, Andhra Pradesh, urban, aged 54 years, Class 9]

We should not teach them. It would be like spoiling our own children. If we teach them about it, they may try to experiment. Even now, school students read all kinds of dirty magazines, and if we teach them, they will get even more spoilt. [Father, Tamil Nadu, urban, aged 49 years, Class 8]

\section{Summary}

Both mothers and fathers, irrespective of region or urban-rural setting, described a range of factors that inhibited them from discussing sexual and reproductive health matters with their children. Most often cited were cultural norms that made it unacceptable for parents and children to discuss these matters. Many of these parents reported 
for example, that parents in their setting did not speak of such matters to their children, and that young men and women, particularly young women, should not be informed about sex until marriage, and that once married, they would come to know about it automatically. Others suggested that in their cultures, children as young as the child in question (all aged 15 and above) were too young to be informed about these matters. A second leading factor inhibiting communication, also closely associated with cultural taboos, was discomfort due to shyness and embarrassment, both on the part of parents themselves and on the part of their children. In many ways, parents reported that they were too shy to speak to their children, and alternately, that their children were too shy to speak to them. While not an obstacle, several of these parents noted their children's preference for obtaining this information from the extended kin network, thereby reducing their need to communicate on these topics with their children. A third leading reason parents gave for their limited communication was their perception that youth today became aware of these matters on their own-through interactions in the school setting, through television and books, through friends, and less often, through the more traditional providers of this information, that is, family elders, older siblings and/or sisters- or brothers-in-law. A fourth factor, expressed by a few parents, was the concern that communicating about sexual matters would be perceived by young people as a license to experiment with sex; in the words of one parent, "it is like parents teaching that."

The kinds of obstacles described by mothers and fathers and by rural and urban parents were, on the whole, similar. Mothers were, however, considerably more likely than fathers to report discomfort and shyness experienced by themselves as well as their children, as an obstacle, and somewhat more likely than fathers to suggest that children came to know these matters on their own. Fathers were more likely, in contrast, to report fears that children would go astray if informed by their parents about sexual and reproductive health matters. Likewise, urban mothers and fathers were less likely than their rural counterparts to report that they were uncomfortable or shy about discussing these matters with their children; conversely, urban mothers and fathers were more likely than their rural counterparts to report that their children were shy or uncomfortable to discuss these matters with them. 


\section{Perspectives of parents who favour the provision of information on sexual and reproductive health matters to their children}

This chapter focuses on the perspectives of parents who recognised the need for their children to be informed about sexual and reproductive health matters, irrespective of whether they had discussed these matters with their children, and, particularly, the preferred channels through which this information should be imparted. Findings in this chapter contrast with the perspectives of youth, as reported in the survey (IIPS and Population Council, 2010). Indeed, the extent to which youth felt a need for information on sexual and reproductive health matters was evident: about four in five young men and women ( $83 \%$ and $78 \%$, respectively) maintained that youth need information on these matters. A relatively small proportion of these youth reported a preference for receiving this information from a parent, and young women were considerably more likely than young men to so report-one in three young women $(34 \%)$ compared to about one in twenty young men $(6 \%)$.

While relatively smaller proportions of mothers and fathers expressed views similar to those expressed by youth, and notwithstanding the limited parentchild communication observed in Chapter 3 and the significant obstacles to communication observed in Chapter 4, many parents did agree that young people need information about the physical changes associated with puberty as well as sex, pregnancy and sexually transmitted infections/HIV (Table 5.1).

Findings suggest that mothers were far more likely to adhere to traditional cultural norms about the provision of information on sexual and reproductive health matters-even the physical changes associated with puberty - to their children, and far more reluctant than fathers to favour such practices. As seen in Table 5.1, Panels A and B, respectively, a total of 39 of the 145 mothers (27\%) compared to 79 of the 97 fathers (81\%) who had elaborated on the reasons for their limited communication with their children on these matters and/or their preferences about whether their children should obtain this information, believed that youth must be informed about such matters. Moreover, urbanrural differences were notable among fathers, with 28 of the 43 fathers in urban areas (65\%) compared to 51 of the 54 in rural areas (94\%), perceiving the importance of informing their children about these matters. Urban-rural differences, in contrast, were narrow among mothers: 14 of the 47 urban mothers $(30 \%)$ and 25 of the 98 rural mothers (26\%) recognised the importance of providing this information to their children.

Many parents spoke in generalities of the importance of conveying information on sexual and reproductive health matters to their children, without necessarily identifying the preferred source of such information. However, a large group of these parents-14 mothers (10\%) and fathers (39 or $40 \%$ ) - argued that the school was best suited to provide this education to their children. In contrast, urban-rural differences were narrow: $6(13 \%)$ of the 47 and $8(8 \%)$ of the 98 urban and rural mothers, 
Table 5.1

Parent preferences about whether youth should be informed about sexual and reproductive health matters
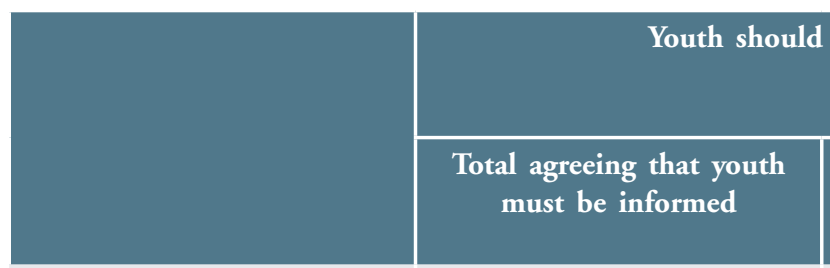

\begin{tabular}{c} 
be informed \\
\hline $\begin{array}{c}\text { School/other programmes } \\
\text { should provide this } \\
\text { information }\end{array}$ \\
\hline
\end{tabular}

\begin{tabular}{c}
$\begin{array}{c}\text { Total whose narratives } \\
\text { elaborated on the nature } \\
\text { of discussion* }\end{array}$ \\
\hline
\end{tabular}

\section{A. MOTHERS}

Bihar

Jharkhand

Rajasthan

Maharashtra

Andhra Pradesh

Tamil Nadu

Total

\section{Urban}

Rural

8

7

6

12

6

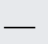

39

14

25

\section{B. FATHERS}

Bihar

Jharkhand

Rajasthan

Maharashtra

Andhra Pradesh

Tamil Nadu

Total

Urban

Rural

8
6
6
6
-

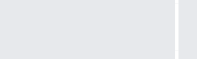

(2)

3

2

2

7

-

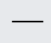

14

6

8

2

1

7

8

6

15

39

16

23
23

27

21

29

34

11

145

47

98

5

12

19

20

24

17

97

43

54

Note: *Reasons for not discussing these issues, for discussing these issues, and preferences about the provision of information to their daughters/sons.

respectively; $16(37 \%)$ and $23(43 \%)$ of the 43 and 54 fathers, respectively. State-wise differences were notable. Indeed, seven of the 14 mothers who favoured school-based sexuality education came from Maharashtra; not a single mother from the southern states reported a preference for schoolbased programmes. In contrast, of the 39 fathers who favoured the provision of sexuality education in the school setting, just ten came from the northern states (three from Bihar and Jharkhand and seven from Rajasthan), compared to 29 from the western and southern states.
Most of the parents who favoured the provision of sexuality education suggested that schools were an acceptable option because of the difficulties or cultural taboos experienced by parents in communicating on these topics. While this perception was implied in the narratives of many parents, it was best articulated by parents from Maharashtra, as most of the quotes below suggest:

Yes. We should give them such information. It should be given in the Madarsa or the Anganwadi centre. If these things are told to them 
in their school, then it would be better (than in the home). [Mother, Bihar, rural, aged 35 years, no education]

Yes. They (children) must discuss (about sexual matters) but not with their parents. If the teacher gives this education then it is good. If the goldsmith pricks the ears then it will not pain. [Father, Bihar, urban, aged 48 years, Educational attainment level not available]

Such information should be given. If parents are able to talk to their children about such things then they should give such information otherwise such information should be given by the school. But, since everybody gets such an experience (sex), it would be better if this information is given in school. [Mother, Maharashtra, rural, aged 39 years, Class 9]

Such education should be provided in colleges. In their virgin state, they (children) should receive such education. They should get such information through education only. Guardians will not be able to guide them on this aspect; they will not talk about sexual relationships. [Father, Maharashtra, rural, aged 55 years, graduate]

The school must give this information to boys and girls according to their age group. If boys and girls are given this education in school, they will get good information and their doubts will be cleared. Children can speak freely in school; as there are boys and girls of their own age, they can discuss among themselves and clear their doubts. At home, boys and girls cannot speak to their parents so freely, because all the family members are present. They speak only about work and about here and there (general topics), but don't discuss sex education. That is why it is necessary to give them sex education in school. [Mother, Maharashtra, rural, aged 49 years, Class 4]

A few parents acknowledged that the responsibility for communicating matters concerning sexual and reproductive health with children lies with parents and/or other family members, although they acknowledged that they had never communicated on these matters with their children.

Yes, they should definitely tell their children. By giving an example of 'someone' (a fictitious person), parents should tell their children about these things so that children can understand these matters properly and do not feel helpless. [Mother, Bihar, rural, aged 36 years, no education]

They will say that they have come to teach bad things, 'phaltu baat.' This information should first be given in the family itself and then by others. I mean to say that they (children) should be given such information at the proper level. What is the need for children to go to outside organisations? They should get this information from their father and mother; that will be better. [Mother, Bihar, rural, aged 44 years, Class 10]

Some parents suggested that it was for children to initiate the discussion, and once initiated, their parents would communicate with them.

It should be discussed but parents do not talk about it. If there is some difficulty, it is better if the child asks; so that there is no problem. If they do not ask how would anyone come to know what the difficulty is? If they do not tell us, how will we come to know? [Mother, Rajasthan, rural, aged 40 years, no education]

He has never talked to us about it. He has not said anything. Therefore, we have also not said anything. [Mother, Rajasthan, rural, aged 50 years, no education] 
This is only possible if children ask about

it. Guardians, on their own, will not tell their children about such matters. [Father, Maharashtra, rural, aged 55 years, graduate]

They have to ask when they begin to think about such things. Then we will tell them. [Father, Andhra Pradesh, rural, aged 47 years, Class 5] (If he had asked), I would have informed him for sure. I would have explained the situation and the reason for health problems. I would also have explained to him how youth get spoilt by going on the wrong path. I would have even asked him to avoid certain behaviours. [Father, Tamil Nadu, urban, aged 57 years, Class 10]

Some of these parents suggested that parents themselves need to be educated about sexual and reproductive health matters before they can convey them to their children. For example:

If the girl asks her mother, then she should be able to tell her. So, such knowledge should be given to the parents. [Mother, Bihar, rural, aged 35 years, no education]

When the parents understand it, only then can they tell their children. They should know what a sexual relationship means. What AIDS is. What are the diseases with which one can get infected. If they understand these things, they will be in a better position to explain these matters to their children: whether they should do things in a certain manner or not; that they should not reuse a syringe used by another person as it is not safe, and things like that. [Mother, Bihar, rural, aged 36 years, no education]

The person who speaks about this must give correct information... If we want to speak on sex education then we must have knowledge. [Father, Maharashtra, rural, aged 46 years, Educational attainment level not available]

\section{Summary}

Although most parents did not communicate with their children about sexual and reproductive health matters, not even the physical changes associated with puberty, several parents acknowledged the need to provide children with information on these issues. Wide differences were observed between fathers and mothers. Mothers were far more likely to adhere to traditional cultural norms about the provision of such information to their children than were fathers. Indeed, almost three times as many fathers as mothers favoured the provision of information on sexuality-related matters to their children. Urbanrural differences were narrow among mothers; among fathers however, while almost all those in rural areas perceived the importance of informing their children about these matters, two in three urban fathers so perceived.

Many parents spoke in generalities of the importance of conveying information on sexual and reproductive health matters to their children, without necessarily identifying the preferred source of such information. Wide gender differences were apparent: a considerable number of fathers and far fewer mothers ( $81 \%$ versus $27 \%$ ) expressed agreement on providing information on sexuality-related matters and also argued that the school was best suited to provide this education to their children ( $40 \%$ versus $10 \%)$. State-wise differences were also notable. Indeed, it was fathers of young people, particularly fathers in the three states characterised by high levels of HIV/AIDS (Andhra Pradesh, Maharashtra and Tamil Nadu), who were most in favour of sexuality education and preferred the school setting as appropriate for the purpose; in contrast, few fathers in the low HIV prevalence states of Bihar and Jharkhand expressed such a preference. Statewise patterns were not as clear among mothers; even so, half of those favouring school-based sexuality 
education came from a single state, Maharashtra. Clearly, both the HIV situation and deeplyentrenched cultural norms conditioned the priority that mothers and fathers placed on providing sexuality education to their children. Nevertheless, that a sizeable proportion of parents, particularly fathers and especially those from the high HIV prevalence states, approved of sexuality education, suggests that concerns about the threat posed by HIV/AIDS to their growing children, led them to question the traditional cultural taboos proscribing the communication of sexual and reproductive health matters, and acknowledge the need for sexuality education. This willingness to change (also observed in the findings reported in Chapter 3) and their recognition of the relevance of sexuality education in their children's lives, holds promise for engaging parents' support for efforts to promote the sexual and reproductive health of young people.

Parents' perspectives about the relevance of sexuality education resulted in three broad groups of suggestions to enable the transmission of information relating to sexual and reproductive health to young people. Some parents argued that parents would not be able to communicate this information, and stressed the need for the school system to take on this task. A second group believed that such information should be transmitted by parents, and that parents themselves needed to be educated in what to say and how to convey messages. A third group maintained that they were prepared to discuss these matters with their children, but expected their children to raise the topic with them rather than initiating the discussion themselves. 


\section{CHAPTER 6}

\section{Moving forward}

This chapter highlights the lessons learned for programming to enhance parent-child communication on sexual and reproductive health matters, and outlines areas for further research on parent-child interaction on these issues. Sexual and reproductive health matters have been described in terms of physical changes associated with puberty, as well as sex, pregnancy and sexually transmitted infections/HIV.

\section{Recommendations for programmes}

The patterns of parent-child communication on sexual and reproductive health matters observed among parents in all six states, irrespective of the state's level of development or the extent of gender equity characterising the state, clearly highlight the importance of efforts to encourage closer and more supportive communication between parents and young people. Programmes are therefore urgently needed that orient both mothers and fathers, and that inform parents about effective parenting styles and the need for and importance of close communication with children.

\section{Inform parents about sexual and reproductive health matters}

While acknowledged by relatively few parents, it is likely that parental inhibitions arise also because of their own lack of knowledge of sexual and reproductive health matters and their perceived inability thus to respond to their children's questions. Findings suggest that even among those who did provide information to their children, this information was not always accurate. These findings call for adult sexuality education programmes that inform men and women about sex and reproductive processes, pregnancy and sexually transmitted infections/HIV, reproductive rights, and more specifically, the physical changes associated with puberty.

\section{Break down parents' misconceptions about communicating with children on sensitive matters}

It is clear that parents hold many misconceptions, for example, that girls should not be informed about menstruation until it happens or that young men and women, particularly young women, should not be informed about sex and reproduction until marriage, that youth will interpret any communication on matters relating to sexual life as a licence to experiment with sex, and that young people are well-informed about sexual matters through the media and friends. Programmes for parents need to dispel these misconceptions and highlight the need for and acceptability of providing their children this information themselves.

\section{Ensure that communication about menstruation is timely and comprehensive}

As mentioned above, most mothers agreed that girls need not be informed about menstruation until it happens. Thus, it is not surprising that many women described their daughters' first experience of 
menstruation as traumatic, characterised by tears, fears that their parents would be angry, and concerns that the blood signified their ill-health. Many women also described their communication with their daughters following the initiation of menstruation as defined by the mechanics rather than the meaning of menstruation - "how to use the cloth" and dos and don'ts (don't talk to boys, don't come inside the kitchen etc) associated with menstruation, rather than the menstrual cycle, and its links with pregnancy and reproduction. Efforts are needed that inform parents about the need for providing timely information to girls before and not after they start menstruating, and that age-appropriate information is provided that explains the menstrual cycle and its links to pregnancy.

\section{Address discomfort and embarrassment experienced by both parents and children}

Efforts must also be made to reduce parental inhibitions about talking about the physical changes associated with puberty and/or sexual matters with their children. Discomfort due to embarrassment and shyness were expressed by many parentsparticularly mothers, but also fathers; they were also described as characterising their children's reluctance to communicate with their parents on these issues. Efforts are needed that break down inhibitions at both parent and child levels. Interventions that alternate between individual parent and child sessions and combined parent-child sessions would appear to be a promising approach whereby to reduce the discomfort experienced by parents and children, respectively.

Survey findings showed that about one in three young women and fewer than one in ten young men reported that they would like to obtain information on sensitive topics from their parents. At the same time, several parents suggested that they would be ready to discuss issues relating to the physical changes associated with puberty, and issues relating to sex and reproduction if their children initiated the discussion. While programmes that focus on parents are needed-more so when perceived by parents themselves, life skills and sexuality education programmes should also build young people's skills and confidence and enable them to overcome their inhibitions in discussing sensitive and non-sensitive matters with their parents. Lessons may be drawn from programmes for young people-particularly for the school-going-conducted elsewhere that include activities or homework for young people to do with their parents that enable learning and, at the same time, provide an opening for parents to initiate discussion on sexual and reproductive health matters with their children.

\section{Enable parents and young people to question prevailing norms}

Findings have reiterated the serious social proscriptions with puberty that fall on young women, and, to a lesser extent, young men, and that the content of communication from parents to children focuses on the importance of conforming to and perpetuating prevailing social, gender and relationship norms. Programmes for parents and for young people need to enable parents, as much as young people, to clarify values, to question traditional norms, including the social and genderrelated constraints that limit young people from attaining their full potential; effective community mentors and local role models are needed that allay parents' concerns about allowing their children to deviate from traditional norms and behavioural expectations. 


\section{Make efforts towards more gender egalitarian and open communication}

Findings have suggested the gendered nature of communication between parents and children. While content is limited, communication is most likely among mothers and daughters. To a more limited extent, communication is observed between fathers and sons, but in general, fathers rarely communicate with their children on sensitive matters. Programmes are needed that focus on men and boys: that involve fathers in communicating more effectively with their sons and daughters on sexual and reproductive health matters, and those that ensure that sons are not excluded from discussions on such sexual and reproductive health matters as the physical changes associated with puberty, sex, pregnancy and infection.

In general, programmes must encourage greater openness and interaction between parents and children and enable the adoption of more genderegalitarian child-rearing practices. While precedents are unfortunately unavailable, promising approaches through which to engage parents must be explored and may include such formal mechanisms as parent-teachers' associations and other non-formal mechanisms such as those relying on community opinion leaders and community groups.

\section{Promote sexuality education in the school setting and dispel parental fears about its provision}

Many parents, even those who had not discussed sensitive matters with their children, agreed about the need for sexuality education for young people. Others, who did not so agree, reported that youth obtained this information on their own in school and through friends. Clearly, notwithstanding the furore created about India's Adolescence Education Programme and the need to provide life skills education to school-going youth, parents do indeed acknowledge their own reluctance to communicate on these matters with their children, and perceive the school as an acceptable setting from which to impart sexuality education to children. While enhancing close communication between parents and children is central for youth development, addressing norms and breaking down inhibitions may not show results in the shorter term; it is important therefore, that keeping parents' own preferences in mind, schools are equipped and empowered to communicate with young people on sexual and reproductive health matters, including the physical changes associated with puberty, sex, pregnancy and infections, and that the Adolescence Education Programme and similar efforts are widely implemented. The positive attitudes towards sexuality education held by some parents, particularly fathers, suggests that engaging parents, and particularly the fathers of school-going children, may facilitate community acceptance for the promotion of schoolbased sexuality education programmes.

Findings have suggested that several parentsmothers, much more than fathers-oppose sexuality education for their children, in or outside of schools. It is particularly important that programmes understand and dispel their fears and concerns and convince them of both the need for school and NGO programmes to impart this education to their children, and for them to communicate better with their sons and daughters on these matters.

\section{Recommendations for research}

Our study is one of the few studies that have explored the perspectives of parents with regard to communication about sexual and reproductive health matters. While it has presented many interesting insights, a number of issues clearly need further exploration. 
First and foremost, quantitative research is required to complement the insights from our entirely qualitative study design. How parents perceive their communication with their children, the obstacles and misconceptions they face in informing their children about sensitive matters, and their preferences for doing so need to be documented.

Second, research elsewhere has shown that parents and children often have diverging perceptions about their communication on sensitive topics (Newcomer and Udry, 1985) and research is needed that will assess the extent to which this divergence is evident in India, and the effect of convergence or divergence in perceptions on youth behaviours in the sexual and reproductive health arenas.

Third, research is needed that explores the links between close parent-child communication and the transition into sexual life, the extent of risk-taking and the extent of informed sexual and reproductive decision-making.

Finally, there is need to implement and test the effectiveness of interventions designed to improve parent-child communication and interaction.

\section{Conclusion}

There is enough evidence from around the world that parents matter, and that supportive communication between parents and children enables young people to make a safe and confident transition to adulthood. Our study, one of the first from India to probe parental perspectives, suggests that parents are indeed concerned about their children's transition into sexual life, but are constrained by traditional norms, lack of information and limited skills from communicating with and providing them the supportive environment needed to make this transition. It is important that efforts are initiated that enable parents to overcome these constraints. 


\section{References}

Abraham, L. and K.A. Kumar. 1999. "Sexual experiences and their correlates among college students in Mumbai city, India.” International Family Planning Perspectives, 25(3): 139-46.

Alexander, M., L. Garda, S. Kanade et al. 2006. "Formation of partnerships among young women and men in Pune District, Maharashtra." New Delhi: Population Council.

Altekar, A.S. 1962. The Position of Women in Hindu Civilization. Delhi: Motilal Banarasidas.

Aspy C.B., S.K. Vesely, R.F. Oman et al. 2007. "Parental communication and youth sexual behaviour." Journal of Adolescence, 30(3): 449-66.

Biddlecom, A., K. Awusabo-Asare and A. Bankole. 2009. "Role of parents in adolescent sexual activity and contraceptive use in four African countries." International Perspectives on Sexual and Reproductive Health, 35(2): 72-81.

Bettinger, J.A., D.D. Celentano, F.C. Curriero et al. 2004. "Does parental involvement predict new sexually transmitted diseases in female adolescents?” Pediatrics and Adolescent Medicine, 158: 666-670.

Blum, R.W. and K.N. Mmari. 2005. "Risk and protective factors affecting adolescent reproductive in developing countries." Geneva: World Health Organization.

Cui, N., M. Li. and E. Gao. 2001. "View of Chinese parents on the provision of contraception to unmarried youth.” Reproductive Health Matters, 9(17): 137-145.

Di Clemente R.J., G.M. Wingood, R. Crosby et al. 2001. "Parent-adolescent communication and sexual risk behaviours among African American adolescent females." Journal of Pediatrics, 139: 407-412.

Garda, L. and M. Alexander. 2009. "Parent-child connectedness: A pressing need to be addressed in rural and urban India." Paper presented at XXVI IUSSP International Population Conference, Marrakech, Morocco.

Hollander, D. 2007. "Program for fathers helps them talk to young sons about sex and HIV risk." Perspectives on Sexual and Reproductive Health, 39(4): 248-249.

International Institute for Population Sciences (IIPS) and Population Council. 2010. "Youth in India: Situation and Needs 2006-2007." Mumbai: IIPS.

Joint United Nations Programme on HIV/AIDS (UNAIDS). 2008. "Report on the Global AIDS Epidemic." Geneva: UNAIDS.

Kiragu, K., C. Watson, M. Muhwezi et al 2007. "Straight Talk Campaign in Uganda: Parent Survey." Washington, DC: Population Council.

Kirby, D. 2007. "Emerging Answers 2007: Research findings on programs to reduce teen pregnancy and sexually transmitted diseases." The National Campaign to Prevent Teen and Unplanned Pregnancy. Accessed on 21 July, 2011 at http://www.thenationalcampaign.org/ea2007/. 
Kumi-Kyereme, A., K. Awusabo-Asare, A. Biddlecom et al. 2007. "Influence of social connectedness, communication and monitoring on adolescent sexual activity in Ghana." African Journal of Reproductive Health, 11(3): 133-147.

Lambert, H. and K. Wood. 2005. "A comparative analysis of communication about sex, health and sexual health in India and South Africa: Implications for HIV prevention.” Culture, Health and Sexuality, 7(6): 527-541.

Lederman, R.P., W. Chan and C. Roberst-Gray. 2004. "Sexual risk attitudes and intentions of youth aged 12-14 years: survey comparisons of parent-teen prevention and control groups.” Behavioural Medicine, 29(4): 155-163.

Li, X., B. Stanton and S. Feigelman. 2000. "Impact of perceived parental monitoring on adolescent risk behaviour over 4 years." Journal of Adolescent Health, 27: 49-56.

Luwaga, L.C.N. 2004. "Parent-adolescent communication on sexuality in the context of HIVIAIDS in Uganda: An exploratory study." Bergen: Research Centre for Health Promotion.

Mahajan, P. and N. Sharma. 2005. "Parents attitude towards imparting sex education to their adolescent girls." Anthropologist, 7(3): 197-199.

Mehra, S., R. Savithri and L. Coutinho. 2002. "Sexual behaviour among unmarried adolescents in Delhi, India: Opportunities despite parental controls." Paper presented at the 2002 IUSSP Regional Population Conference, Bangkok, June.

Meschke, L.L., S. Bartholomae and S.R. Zentall. 2000. "Adolescent sexuality and parent-adolescent processes: Promoting healthy teen choices." Family Relations, 49: 143-154.

Miller, K.S., B.A. Kotchick, S. Dorsey et al. 1998. "Family communication about sex: What are parents saying and are their adolescent listening?" Family Planning Perspectives, 30(5): 218-222 \& 235.

Ministry of Health and Family Welfare (MOHFW). 2006. "Implementation Guide on RCH II Adolescent Reproductive Sexual Health Strategy for State and District Programme Managers." New Delhi: MOHFW, Government of India.

Ministry of Statistics and Programme Implementation (MOSPI). 2008. "New Series (1999-2000) Statement: Gross State Domestic Product at Current Prices." New Delhi: MOSPI, Government of India. Accessed on 27 March 2008 at <www.mospi.nic.in/6_gsdp_cur_9394ser.htm>.

Mohammadi, M.R., S. Alikhani., F.K. Abadi Farahani et al. 2007. "Parents attitudes towards adolescent boy's reproductive health needs and practice in Tehran." Iran Journal of Psychiatry, 2: 13-24.

Newcomer, S.F. and R. Udry. 1985. "Parent-child communication and adolescent sexual behaviour." Family Planning Perspectives, 17(4): 169-174.

Ngom, P., M.A. Magadi and T. Owuor. 2003. "Parental presence and adolescent reproductive health among the Nairobi urban poor." Journal of Adolescent Health, 33(5): 369-377.

Office of the Registrar General and Census Commissioner. 2001a. Age Groups. Accessed on 27 November 2008 at <http://www.censusindia.gov.in/Census_Data_2001/Census_Data_Online/Social_and_cultural/Age_Groups. aspx>.

Office of the Registrar General and Census Commissioner. 2001b. Primary Census Abstract, Total Population: Table A-5, Series 1. New Delhi: Office of the Registrar General and Census Commissioner. 
Roche, K.M., S. Ahmed and R.W. Blum. 2008. "Enduring consequences of parenting for risk behaviours from adolescence into early adulthood." Social Science and Medicine, 66(9): 2023-2034.

Ryan, S., K. Franzetta, J. Manlove et al. 2007. "Adolescents' discussions about contraception or STDs with partners before first sex." Perspectives on Sexual and Reproductive Health, 39(3): 149-157.

Shekhar, M., S. Ghosh and P. Panda. 2007. "Exploring Safe Sex Awareness and Sexual Experiences of Adolescents in Patna." Economic and Political Weekly, 42(48): 48-55.

Shetty, P., S. Kowli and V. Patil. nd. "Attitude of mothers towards sex education of adolescent girls." Regional Health Forum WHO South-East Asia Region (Volume 3). Accessed on 29 March 2011 at http://www.searo.who. int/en/Section1243/Section1310/Section1343/Section1344/Section1351/Section1686_7197.htm.

Soletti, A.B., V. Guilamo-Ramos, D. Burnette et al. 2009. "India-US collaboration to prevent adolescent HIV infection: The feasibility of a family-based HIV-prevention intervention for rural Indian youth." Journal of the International AIDS Society, 19:12(1):35.

Whitaker D.J., K.S. Miller, D.C. May et al. 1999. "Teenage partners' communication about sexual risk and condom use: the importance of parent-teenager discussions.” Family Planning Perspectives, 31(3): 117-21.

Whitaker, D.J. and K.S. Miller. 2000. "Parent-adolescent discussions about sex and condoms: Impact on peer influences of sexual risk behavior." Journal of Adolescent Research, 15(2): 251-273.

World Health Organization (WHO). 2007. "Helping parents in developing countries improve adolescents' health." Geneva: World Health Organization.

Zhang, L., X. Li., I. Shah et al. 2007. "Parent-adolescent sex communication in China." European Journal of Contraception and Reproductive Health Care, 12(2): 138-147. 



\section{Population Council}

Zone 5-A, Ground Floor India Habitat Centre Lodi Road

New Delhi 110 003, India 